\title{
Tratamiento informativo de la corrupción en los medios digitales de Manizales, Colombia*
}

\author{
Informative Treatment on Corruption Issues of \\ Manizales Digital Media
}

Adriana Villegas-Botero ${ }^{1}$

Universidad de Manizales, Manizales, Colombia

avillegas@umanizales.edu.co

https://orcid.org/0000-0002-4978-3259

Yoiver Giraldo-Quintero ${ }^{2}$

Universidad de Manizales, Manizales, Colombia

ygiraldo@umanizales.edu.co

https://orcid.org/0000-0002-1467-5207

Recibido: 11-02-19

Aprobado: 29-05-19

* Este artículo describe un estudio que indagó las características de la información periodística en medios digitales de Manizales sobre temas de corrupción. La investigación fue apoyada por la Universidad de Manizales y se enmarca en la línea Lenguajes y Narrativas del Grupo de Investigación de la Comunicación, perteneciente a la Escuela de Comunicación Social y Periodismo de dicha institución educativa. Participaron los asistentes de investigación Juan Manuel García, Erika Pinilla, Daniela Ramírez y Fernando Alonso Ramírez.

Magíster en Estudios Políticos.

2 Especialista en Gerencia de la Comunicación Corporativa. 


\title{
Resumen
}

Con el objetivo de indagar cómo es el tratamiento informativo de los medios digitales de Manizales, Colombia, sobre la corrupción y utilizando como técnica de investigación la observación metódica, en este estudio se analizaron 586 notas sobre temas de corrupción publicadas por seis medios digitales. Para el análisis de la información se usó el software Question Pro. Los resultados indican que los medios de comunicación prefieren difundir noticias y columnas de opinión relacionadas con hechos de corrupción de índole nacional, ocurridos hace meses o años, mientras que el reporte sobre hechos recientes y locales es más escaso. Las publicaciones visibilizan acciones sobre la lucha contra la corrupción involucrando en las notas fuentes oficiales. Así mismo, los medios publican en mayor medida información sobre prácticas ilegales protagonizadas por funcionarios de alto estatus. Por último, se halló que estos medios de comunicación no aprovechan las posibilidades interactivas que ofrecen los entornos digitales.

Palabras clave: corrupción; medios digitales; interactividad; tratamiento informativo.

\begin{abstract}
In order to inquire the information treatment around corruption within digital media, in Manizales, Colombia, and using methodical observation as a research technique, in this study 586 notes on corruption topics published by six digital media were analyzed. For the analysis of the information, the Question Pro software was used. The results show that media prefers to disseminate news and opinion pieces related to acts of corruption of a national nature, which occurred months or years ago, while the report on recent and local events is more scarce. The publications highlight actions on the battle against corruption by including official sources in the notes. Likewise, media publishes more information about illegal practices carried out by high-status public servants. Finally, it was found that media does not take advantage of the interactive opportunities offered by digital environments.
\end{abstract}

Keywords: Corruption; Digital media; Interactivity; Information treatment. 


\section{Introducción}

De acuerdo con una encuesta realizada por la firma Gallup, en el mes de junio de 2018, para los colombianos la corrupción sigue siendo el principal problema del país, incluso por encima de la salud, el orden público y la seguridad (El Espectador, 4 de julio de 2018). La misma encuesta reveló que el porcentaje de colombianos que cree que la corrupción está empeorando asciende al $85 \%$. Del mismo modo, en el más reciente índice de Transparencia Internacional, Colombia obtuvo una calificación de 37 puntos en una escala que va desde o para países altamente corruptos hasta 100 para países muy honestos (Transparencia Internacional, 2018). Esta calificación es similar a la de años anteriores y sigue ubicando al país como muy corrupto.

Según otra encuesta de la Universidad Externado de Colombia, realizada a empresarios, el 91\% de estos dijo que "en el país es común la entrega de dádivas para lograr la adjudicación de contratos" (El Tiempo, 5 de abril de 2018). El departamento de Caldas se encuentra en un riesgo medio de corrupción, teniendo entidades como la Gobernación de Caldas y la Alcaldía de Manizales, que han perdido terreno en el ítem de control y sanción; lo que significa un retroceso en comparación con mediciones anteriores, según la Corporación Cívica de Caldas (La Patria, 2 de mayo de 2017).

Aún se siguen conociendo nuevos hechos posiblemente relacionados con casos de corrupción en el país, como el de Odebrecht, y en Caldas, en entidades diversas: presunto tráfico de influencias en el Servicio Nacional de Aprendizaje (Sena), en donde están involucrados funcionarios públicos del departamento (Caracol Radio, 21 de febrero de 2018); posibles irregularidades en la contratación del Instituto de Cultura y Turismo; irregularidades en Aerocafé, el cable aéreo a Los Yarumos; el cable aéreo a Villamaría; y licencias urbanísticas entregadas irregularmente a particulares, entre otros (Caracol Radio, 8 de mayo de 2018).

En el conocimiento de estos casos y la configuración de la percepción sobre el fenómeno social de la corrupción, los medios de comunicación juegan un papel relevante al ser organizaciones "con legitimidad social para producir significados que se reafirman en el entramado simbólico de la sociedad" (Ramos, 1995, p. 108), y que influyen en las facetas de la vida de las personas y su comprensión de la realidad (Bryant y Zillmann, 1996).

En consecuencia, los medios de comunicación son instituciones que, según Bourdieu (1997), tienen el derecho a hablar por el capital simbólico con el que cuentan, que les permite, a través del lenguaje, ser agentes dominantes y reconfigurar identidades contemporáneas (González, 2007), e incidir en el pensamiento y las actuaciones de las personas (Unesco, 2016). De acuerdo a Lippman (1955), citado por Lozano (1997), la importancia de la influencia de los medios en la opinión pública radica en que son la conexión principal entre los acontecimientos que se desarrollan en el mundo y la imagen que esos eventos tienen en la mente de los receptores.

Con la incidencia que han tenido las tecnologías en la forma como las personas acceden a la información, los medios de comunicación tradicionales se han visto en la obligación no solo de transmitir esta información en su formato tradicional, -por ejemplo, en físico en el caso de los periódicos- sino también en formato digital, mediante el cual pueden obtener una actualización de las noticias más inmediata e interactiva (Codina et al. 2014).

A propósito de los medios de comunicación digitales, estos también son denominados cibermedios y surgieron con la aparición de la web. Los mismos han logrado fusionar las posibilidades de los medios impresos y audiovisuales, creando nuevas estructuras informativas (Montiel, 2000, p. 35). Lo que les ha permitido distinguirse de otros medios, al poseer sus propias características e idiosincrasia (Pareja, 2003, p. 36).

Teniendo presente lo anterior, este estudio analizó cómo comunican los temas y hechos de corrupción los medios de comunicación digitales de Manizales. 
Por consiguiente, el presente artículo se divide de la siguiente manera: en la primera parte se presenta la revisión de la literatura sobre los principales conceptos que sustentan esta investigación como cibermedios, corrupción, tratamiento informativo, entre otros. Posteriormente, se explica la metodología usada para la recolección y clasificación de las noticias analizadas. Luego se describen los resultados encontrados $y$, finalmente, se presenta la interpretación de estos resultados y las conclusiones finales de la investigación.

\section{Marco teórico}

\subsection{Sobre los medios de comunicación}

De acuerdo con Bourdieu (1995), al estar los medios de comunicación conformados por personas con capital simbólico y cultural y que gozan de reconocimiento social, se convierten en instituciones con poder para crear realidades en torno a la 'verdad', pues estos capitales les permiten constituirse en agentes dominantes, que mediante el lenguaje pueden influenciar a unos agentes dominados.

\footnotetext{
Disponer de los medios de comunicación significa, en la actualidad, poseer un poder social, no tanto por el contenido que transmiten sino por el ambiente que crea, la atención y el mimetismo que despierta. El medio actúa como un espejo que refleja la realidad social y, al mismo tiempo, es el lugar en el que se crea ésta (Castillo, 2011, p. 4).
}

Bourdieu define el capital simbólico como un poder reconocido, a la vez que desconocido, $y$, como tal, generador de poder simbólico y de violencia simbólica (Bourdieu, 1991). El capital cultural hace referencia a la educación recibida por las personas. En este caso, los periodistas que hacen parte de los medios y que les otorgan una licencia social para crear y difundir información a unas comunidades (Bourdieu, 1997). También para presentarse como autores de una noticia y así ganar visibilidad y reconocimiento en busca de aumentar su credibilidad (Túñez y Martínez, 2014). Por lo tanto, según Bourdieu
(1996), citado en Fernández (2012), lo que distingue las posiciones de élite de las demás son diferencias significativas en el capital cultural y simbólico de las personas.

Los medios de comunicación se basan en géneros periodísticos que les dan la posibilidad de presentar la información de diversas maneras. Entre estos géneros, se encuentra la noticia, la crónica, el reportaje, la entrevista y la columna de opinión; además determinan características en la producción de contenidos, creando una diferencia entre información y comentario (Rivas, 1999).

Los medios tienen la capacidad "para graduar la importancia de la información que difunden, otorgando un orden de prioridad y favoreciendo una determinada percepción ciudadana sobre las noticias de la vida pública" (Meyer, 2009, p. 17). Esta información puede ser de autoría de cada medio, resultante de una investigación, en lo que se denomina agenda propia; recolectada a través de una rueda de prensa, mediante la declaración de un funcionario público que hace referencia a la agenda obligada, información original de otro medio y/o contenidos que no están sustentados en un origen específico.

Otro aspecto que determina la naturaleza de la información es el número de fuentes utilizadas en una noticia y el tipo de fuentes que se incluyen, puesto que pueden proceder de entidades del poder ejecutivo, poder político, poder judicial, órganos de control, sociedad civil, academia, sector privado, ciudadanos particulares, entre otros (Ruiz y Albertini, 2008).

El establecimiento de la agenda incluye el proceso de producción de las informaciones y el papel que los periodistas y los propios medios tienen a través del diseño y aplicación de la política editorial (informativa). La producción de información incluye elementos como el tratamiento, que es la valoración cualitativa que se hace de los hechos; la frecuencia y la amplitud, que representan la valoración cuantitativa de los eventos o de las fuentes; y que está representado por el número de veces en que se 
presenta un tema o fuente y el espacio que los medios le conceden (Paz, Romero, Díaz, Rojas y Vargas, 2009).

\subsection{Sobre los medios digitales}

La irrupción de internet, en la década del 90, originó el inicio de varios cambios para los medios de comunicación tradicionales, los cuales, al notar el auge de las Tecnologías de la Información y la Comunicación (TIC) se han visto obligados a incursionar en las plataformas digitales. Con el propósito de estar a la vanguardia en la difusión de la información, puesto que cada vez son más las personas que consultan noticias y otro tipo de contenidos en dispositivos tecnológicos (Franco, 2016).

Retomando a Codina et al. (2014), un medio digital se caracteriza por utilizar una plataforma digital interactiva en línea -bien en forma de sitio web o bien en forma de aplicación para la web móvil- para la publicación de sus contenidos.

\footnotetext{
Las motivaciones para la apertura de estos canales son diversas: incremento de la credibilidad o de un cierto feedback del usuario-lector hacia el productor, mero incremento del tráfico, mayor publicidad y gestión de la imagen de marca, fidelización de la audiencia, hasta la oportunidad para que los ciudadanos debatan los acontecimientos ofrecidos por los periódicos en internet (García, 2018, p. 115).
}

De acuerdo a Montiel (2000), los también llamados cibermedios tienen su fortaleza en poder fusionar el medio impreso y audiovisual e incorporar otros elementos como hipervínculos, infografías, etiquetas, entre otros; con el propósito de incentivar la participación de los internautas y la democratización de la información. Salaverría (2017) subraya que estos medios digitales se diferencian de los tradicionales gracias al "dinamismo que ofrece el soporte en línea a través de la aplicación de técnicas hipertextuales, multimedia e interactivas y frecuente actualización" (p. 22). De esta manera, permite a los periodistas y a las instituciones mediáticas incluir más detalles en sus publicaciones.
"Tres son los rasgos distintivos del ciberperiodismo sobre los cuales se asienta la disciplina: la multimedialidad, la interactividad y la hipertextualidad" (Masip, Díaz-noci, Domingo, Micó-Sanz y Salaverría, 2010, p. 569). Estos elementos pueden aumentar la relevancia de la noticia, haciéndola -a ojos del público- más atractiva e interesante (Canavilhas, 2007).

A propósito de la interactividad mencionada en el párrafo anterior, este concepto es entendido por Hoffman y Novak (1996) desde la capacidad que tiene una máquina de responder a las solicitudes de un ser humano. Jensen (1998) complementa la anterior definición al mencionar que la interactividad hace referencia a la relación entre un ser humano y un sistema informático, y la capacidad de este último de responder a solicitudes a través de links y vínculos en general.

Para concluir la explicación de los medios digitales, es oportuno citar a Castells (2006), quien afirma que:

\footnotetext{
Internet y las tecnologías digitales han transformado el proceso de trabajo de periódicos y medios de comunicación de masas en toda regla. Los periódicos se han convertido en organizaciones conectadas en red internamente que se conectan globalmente a redes de comunicación en Internet. Además, los elementos en línea de los periódicos han inducido la conexión y sinergias con otras organizaciones de noticias y medios de comunicación. Las redacciones de periódicos, televisiones y radios se han transformado con la digitalización de las noticias y el incesante procesamiento global-local. Así pues, la comunicación de masas en el sentido tradicional ahora también es una comunicación basada en Internet tanto en su producción como en su transmisión (p. 101).
}

\subsection{Sobre corrupción}

Con relación a la corrupción, autores como Brei (1996) y White (2013) aseguran que lo que diferencia a un acto corrupto de otro tipo de acto es que, a través del mismo, se tiene como objetivo lograr un beneficio propio en detrimento 
de otros individuos y grupos sociales. Este detrimento se lleva a cabo a través de diferentes conductas como soborno, fraude, clientelismo, concusión, cohecho, entre otras prácticas (Pérez y da Silva, 2015).

Ahora, aunque según Ángel y Fuentes (2015), el mayor obstáculo para ofrecer una definición consensuada sobre este fenómeno social es que la corrupción es percibida de diferente manera de acuerdo al lugar donde se genere, varios autores se han atrevido a clasificar la corrupción en distintas categorías.

Por ejemplo, Solimano, Tanzi y Del Solar (2008) afirman que puede clasificarse de acuerdo al tipo de agente involucrado. Siendo así, se puede distinguir entre corrupción estatal, donde están involucrados funcionarios del estado; corrupción política, que se lleva a cabo por parte de partidos políticos; corrupción privada, efectuada por empresas con ánimo de lucro; y corrupción no gubernamental, donde se ven involucradas ONG, grupos religiosos y entidades sin ánimo de lucro.

Asimismo, Vargas (2009) afirma que la corrupción puede clasificarse en colores. De acuerdo con este autor, existe una corrupción negra, que se refiere a actos corruptos a gran escala y donde participan funcionarios de alto estatus; corrupción gris, protagonizada por actos corruptos de mediana magnitud cuyo origen no se conoce con exactitud; y corrupción blanca, que se evidencia cuando ciudadanos llevan a cabo prácticas naturalizadas como sobornar a un policía de tránsito para evitar la inmovilización de un vehículo.

Por otro lado, Chibnall y Saunders (1977) afirman que la corrupción puede ser vista como una clasificación negociada de un comportamiento, antes que como una cualidad inherente al comportamiento mismo de una persona; y Brito (2016) argumenta que la corrupción implica una alteración del orden institucional y normativo de una sociedad. Añade, además, que este fenómeno social debe estudiarse desde tres perspectivas: la moralista, acto inherente a la naturaleza humana; la integracionista, (las conductas corruptas subsanan las deficiencias de los sistemas sociales, políticos y económicos); y la racionalista, (busca mecanismos alternos de solución a los procesos).

Otra tipología de la corrupción es concedida por Ángel y Bates (2014), quienes argumentan que ésta puede ser entendida en primera medida como una decadencia invasiva. De acuerdo con estos autores, lo anterior significa que este fenómeno social se convierte en un problema a largo plazo para la sociedad, al presentarse como una plaga natural que ataca a instituciones y personas a través del tiempo.

De igual manera, la corrupción también puede ser comprendida como una práctica ilegal cuando es protagonizada por agentes particulares que llevan a cabo actos donde claramente se viola la ley, y con los cuales buscan que algunas personas obtengan beneficios privados (Ángel y Bates, 2014, p. 10). Asimismo, en esta concepción de la corrupción, las acciones son cometidas por agentes específicos y se diferencia del anterior enfoque al no percibir la corrupción como una condición de un sistema, sino como comportamientos ilegales de personas particulares (Ángel y Fuentes, 2015).

Por otro lado, la corrupción también puede entenderse desde prácticas que no son consideradas ilegales, pero tampoco normales. A diferencia de lo mencionado en el párrafo anterior, esta categorización de la corrupción está más ligada al componente moralista y se genera por el fracaso de las convenciones sociales y no por violaciones a la ley (Ángel y Bates, 2014).

Por último, para Ángel y Bates (2014), las conductas que se enmarcan dentro de este fenómeno social también pueden ser percibidas como acciones poco éticas, las cuales generan que:

(...) los valores de un individuo determinado entren en conflicto con el sistema más amplio de valores de una sociedad. Así, a diferencia de la corrupción como actividad irregular, la corrupción se considera regular y también impropia. A diferencia de la ley, 
este sistema de valores es intangible y puede enredarse en la cultura de una sociedad determinada (p. 15).

Ángel y Bates (2014) también nombran otras dos clasificaciones para la corrupción. Según ellos, esta puede ser entendida como una 'piñata' donde unos agentes hacen regalos a otros con recursos públicos. Además, aseguran que algunos actores de la sociedad perciben la corrupción como normal, cuando es protagonizada por ciertos actos que son repetidos constantemente (p. 17).

Continuando, algunas investigaciones han indagado sobre los medios de comunicación y la corrupción. Por ejemplo, Tirado (2016) encontró que los medios tradicionales superan a los medios digitales en cuanto al número de fuentes citadas en las informaciones sobre corrupción, pero resalta en su estudio que son las publicaciones en plataformas digitales las que citan más fuentes directamente, en comparación con medios analógicos. Los cuales prefieren adicionar mayoritariamente fuentes de manera confidencial.

Por su parte, Martínez (2016) afirma que cuanto más baja es la circulación de noticias, mayor es la corrupción. "Los periódicos que cierran oficinas o despiden reporteros avezados para sustituirlos por jóvenes mal pagados pierden capacidad para monitorear a los gobiernos" (p. 165). Agrega que una prensa comprometida financieramente es más fácil de comprometer éticamente.

Asimismo, Gaibar (2015) halló que gracias a las Tecnologías de la Información y la Comunicación (TIC) existe más independencia económica y política de los medios nativos digitales, que favorece la publicación de informaciones contrarias a los intereses políticos (p. 118). También concluyó que los ciudadanos son más propensos a filtrar información a medios digitales sobre casos de corrupción. Álvarez (1999) resaltó en su análisis que los medios de comunicación son fundamentales para la lucha contra la corrupción, al ser capaces de "vigilar a las autoridades y denunciar el abuso del poder" (p. 236).

\section{Metodología}

Teniendo en cuenta que el objetivo general que enmarca la presente investigación es analizar la manera como se comunican los temas y hechos de corrupción en los medios de comunicación digitales de Manizales, se realizó un análisis del tratamiento informativo a estos medios, utilizando la técnica de observación metódica para sus publicaciones sobre temas de corrupción. La selección de las notas se llevó a cabo entre el 15 de diciembre de 2016 y el 15 de junio de 2017.

Para el análisis de estas, se utilizó el software Question Pro, que permitió ejecutar un mejor cruce de los resultados de las distintas categorías definidas para la investigación: información general, tratamiento informativo, tipologías y contenidos de la corrupción.

En total, se analizaron 586 publicaciones entre los siguientes seis medios digitales: Caracol, RCN, La Patria, De la Realidad, Eje 2l, El Tiempo Café. Todos eran consultados diariamente con el propósito de garantizar la adhesión de las informaciones divulgadas sobre corrupción en el periodo de tiempo definido. Se seleccionaron estos seis medios digitales porque son los medios de comunicación, con soporte web, que tienen información diaria sobre Manizales y Caldas. Si bien en la región existen otras páginas de información local, ellas no tienen actualización diaria (como el caso de Revista Alternativa) o tienen una agenda informativa alejada de los temas relacionados con corrupción (como el caso de Quehacer Cultural, que actualiza diariamente la agenda de actividades culturales de la ciudad). En este orden de ideas, los seis medios elegidos representan la totalidad del espectro mediático de Manizales con soporte web dedicado a noticias de actualidad (al momento en que se realizó la investigación).

Dos de los medios seleccionados, Caracol y RCN, corresponden a las páginas web de las emisoras de mayor audiencia en el país y tienen dentro de su sitio en internet un micrositio para la información local. La información que publican en la web corresponde a la información que sale 
al aire en las emisoras. Otros dos medios analizados, La Patria y El Tiempo, son los sitios web del principal periódico de Manizales (La Patria) y el principal periódico del país (El Tiempo), que desde hace dos décadas cuenta con un segmento específico para información local. Los otros dos medios seleccionados, De La Realidad y Eje $\mathrm{XXI}$, son portales web de creación reciente que tienen únicamente soporte en Internet y una nómina de periodistas reducida, que oscila entre uno y dos colaboradores. De acuerdo con la Fundación para la Libertad de Prensa (FLIP), en 2018 se registraron, en Caldas, cuatro ataques al ejercicio de la libertad de prensa, cifra que ubica al departamento en un riesgo bajo. Ninguna de estas agresiones se relacionó con denuncias sobre corrupción (FLIP, 2018, p. 12).

Con relación al proceso de selección de las notas, se hizo revisión diaria de los contenidos publicados en estos seis medios y se eligieron las piezas que mencionaran la palabra "corrupción" o que, sin mencionarla, aludieran a hechos o conductas relacionadas con este fenómeno social como clientelismo, soborno, etc. Cada información seleccionada fue filtrada en un formato previamente diseñado y, posteriormente, se utilizó para completar el formulario creado en Questión Pro. De esta manera, se garantizó la adhesión de todas las publicaciones y un correcto análisis de estas.

La recolección de la información comenzó en diciembre de 2017 y se sostuvo de manera diaria e ininterrumpida durante seis meses, hasta comprobarse una saturación metodológica: la información que se encontraba sobre el tema dejó de aportar datos nuevos que permitieran ampliar el análisis (Glaser y Strauss, 1967).

\section{Resultados}

\subsection{Características generales}

La Patria es un diario fundado en 1921 y es el principal medio de comunicación de Manizales. El Tiempo es el diario de mayor circulación en Colombia, fue fundado en 1911 y desde marzo de 2001 creó El Tiempo Café, una sección regional que circula todos los días en la edición impresa y también tiene espacio en la web. Caracol y RCN son las cadenas radiales de mayor tradición en Colombia: nacieron en 1948 y ambas cuentan con páginas web que tienen espacios específicos para la información de Manizales y Caldas. Por su parte, De La Realidad y Eje 21 son medios de menos de una década de creación y desde su origen han funcionado de manera exclusiva en internet.

Durante los seis meses en los que se recolectó la información, se encontraron 586 publicaciones sobre corrupción en los seis medios mencionados. No hubo un solo día en que no se registraran publicaciones sobre corrupción en al menos uno de los medios, lo cual evidencia que el tema de la corrupción tiene presencia permanente en los medios locales de Manizales. El resultado final fue de un promedio de 3,22 notas publicadas diariamente sobre corrupción en los seis medios, aunque como puede verse en la Figura 1, las cantidades varían significativamente entre los seis medios: El Tiempo Café publicó cuatro notas sobre corrupción en los seis meses analizados, mientras que Eje 21 publicó 284 y La Patria, 190.

Aunque todos los meses (Figura 2) hubo publicaciones sobre corrupción, durante el período observado, el $26 \%$ de las notas salieron en marzo, siendo este el período con mayor concentración de publicaciones, seguido de febrero con $17 \%$. En cuanto a los días de la semana (Figura 3), el 19\% de las notas apareció los jueves, el 18\%, los viernes y el $15 \%$, los miércoles. La menor cantidad de notas se registró en los días domingos, con un $9 \%$. El domingo suele ser un día de agenda informativa muy concentrada en deportes en los medios radiales. En la prensa se suele abrir espacio para contenidos de largo aliento como crónicas, informes especiales y reportajes. Que los días de la semana en los que se hable de corrupción sean días laborales y no fines de semana coincide con los géneros más utilizados para narrar la corrupción, que son las noticias escuetas (como se verá más adelante).

Con relación a los géneros, el uso de videos, audios e infografías se concentra principalmente 
Figura 1. Medio en el cual se publicó la nota

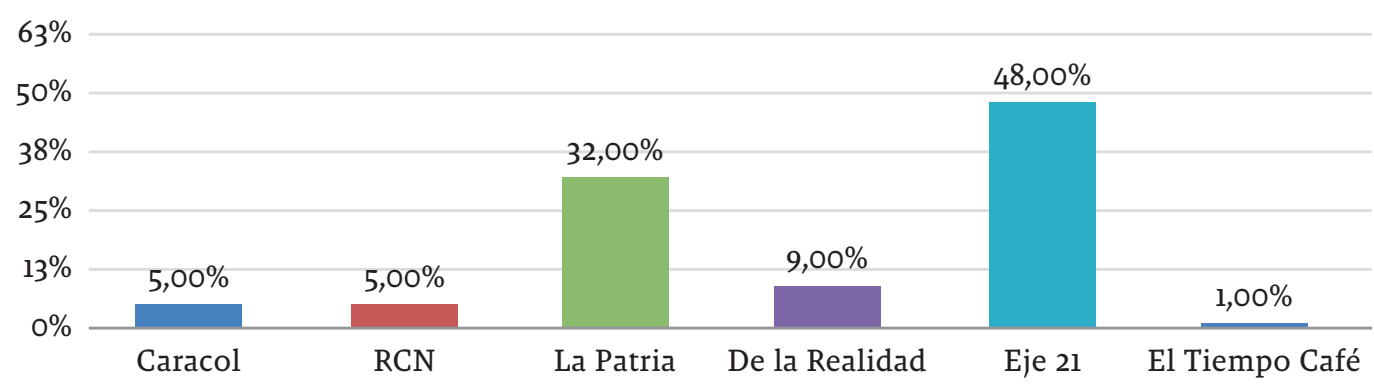

Fuente: elaboración propia.

Figura 2. Mes en el cual se publicó la nota

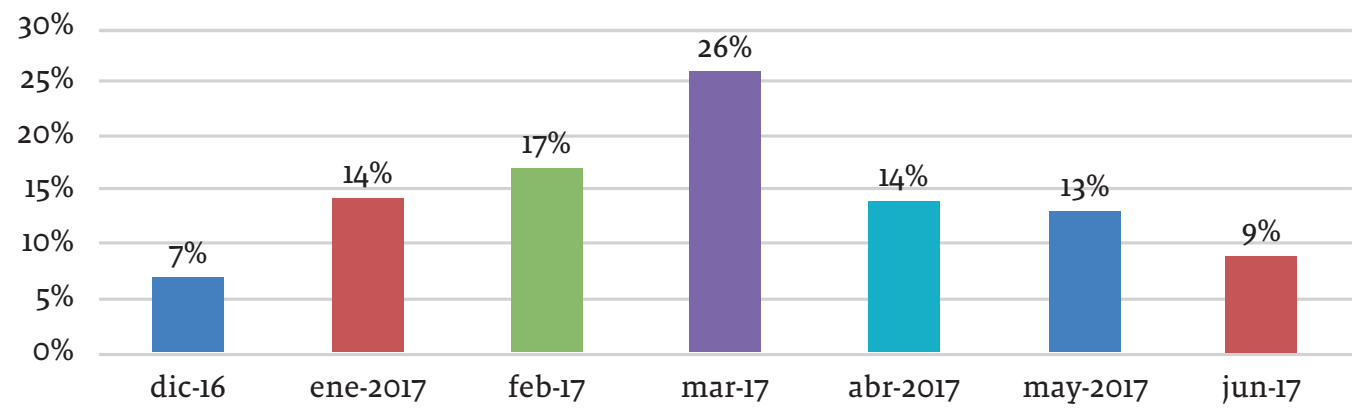

Fuente: elaboración propia.

Figura 3. Día en el cual se publicó la nota

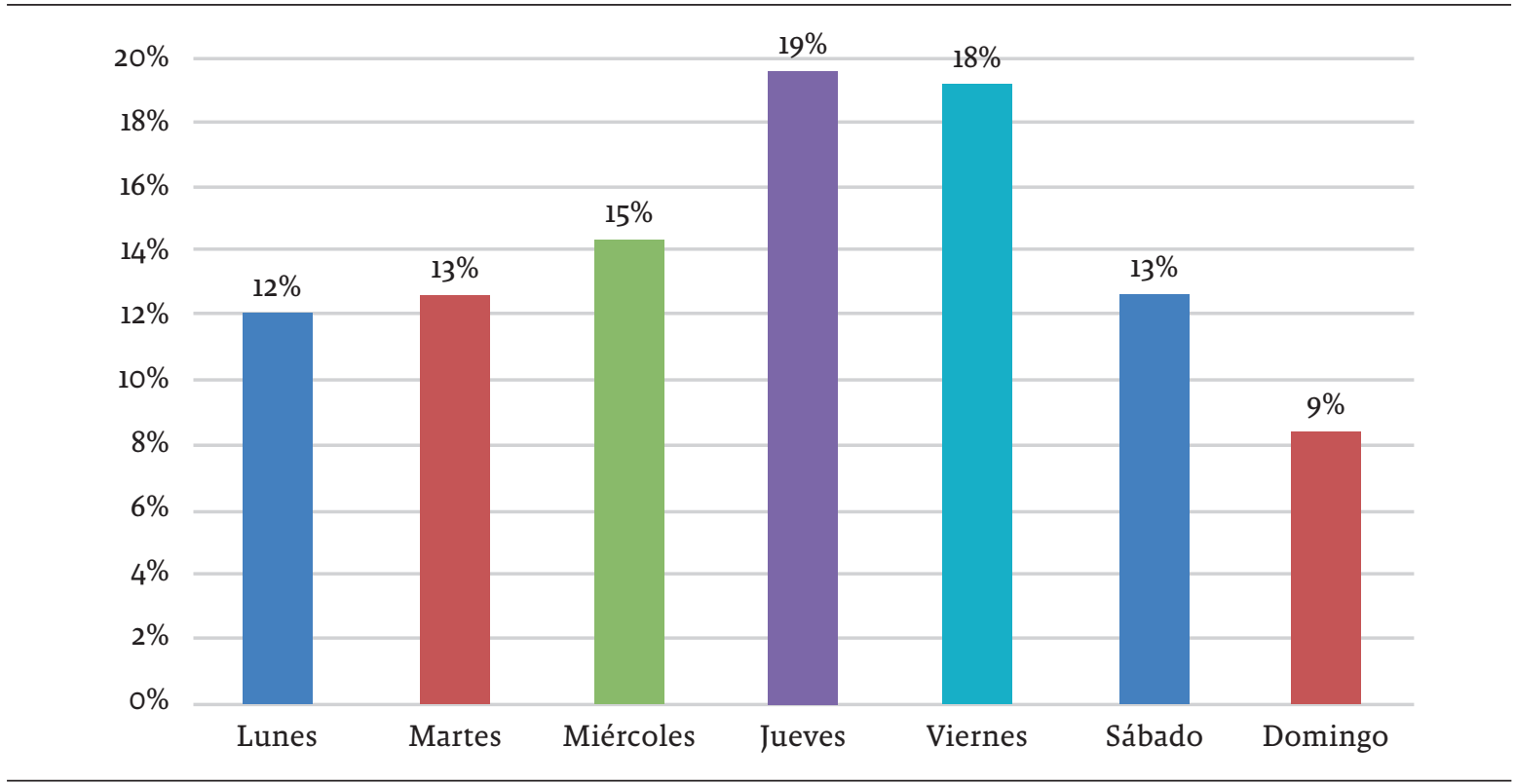

Fuente: elaboración propia. 
en los reportajes. Los hipervínculos aparecen con mayor frecuencia en las noticias, seguidas de las columnas de opinión y los reportajes; y la posibilidad de compartir las notas en redes sociales se concentra en columnas de opinión, noticias, reportajes y entrevistas, en ese orden. Las fotografías son el recurso más utilizado por las noticias y, en segundo lugar, por las columnas de opinión, al igual que las ilustraciones o caricaturas.

El promedio de extensión de los textos publicados en los sitios web fue de 548 palabras, incluyendo títulos, antetítulos, entradillas, créditos, intertítulos, pies de página y demás elementos. La nota más corta fue de 45 palabras y la más extensa, de 2884. Se observa que los medios digitales de las emisoras tienden a publicar notas más cortas, con relación a los medios digitales de los periódicos: las publicaciones de RCN tuvieron una extensión promedio de 317 palabras y las de Caracol, de 423. En contraste con las 565 palabras promedio de $\mathrm{El} \mathrm{Tiempo} \mathrm{Café} \mathrm{y} \mathrm{las} 648 \mathrm{de} \mathrm{La}$ Patria. Los medios exclusivamente digitales se ubican en el medio: el promedio de extensión de las publicaciones de De la realidad fue de 408 palabras y de Eje 21, de 545.

Llama la atención que, aunque el análisis se hizo sobre medios digitales, el uso de recursos multimedia e interactivos es muy escaso. $\mathrm{El} 15 \%$ de las publicaciones consiste únicamente en textos. En el $61 \%$, el principal recurso complementario del texto es una fotografía que puede ser propia del medio, de archivo, descargada de internet o una foto del columnista autor de la nota. El 16\% de las publicaciones incluye, como principal recurso complementario, la posibilidad de compartir la nota en redes sociales (principalmente Facebook, Twitter, correo electrónico y Whatsapp). Tan solo el $2 \%$ de las notas incluye como principal recurso complementario el uso de audios, hipervínculos o ilustraciones, y el $1 \%$ usa infografías (gráficos, mapas, cuadros, tablas, etc.) o videos.

En el período analizado, el uso de videos se concentró principalmente en La Patria y, en menor medida, en De La Realidad y Eje 21. Los demás medios no utilizaron este recurso. Los medios mencionados fueron los que utilizaron hipervínculos, e ilustraciones o caricaturas. Los audios fueron utilizados de manera casi exclusiva por La Patria, con excepción de un audio publicado por De la Realidad. Llama la atención que ninguna de las notas sobre corrupción publicadas en las páginas web locales de las emisoras RCN y Caracol se acompañó de audios. En cuanto a las infografías, su utilización también recae de manera casi exclusiva en La Patria, salvo una publicada por Caracol y otra por Eje 21. Los resultados se indican en la Figura 4.

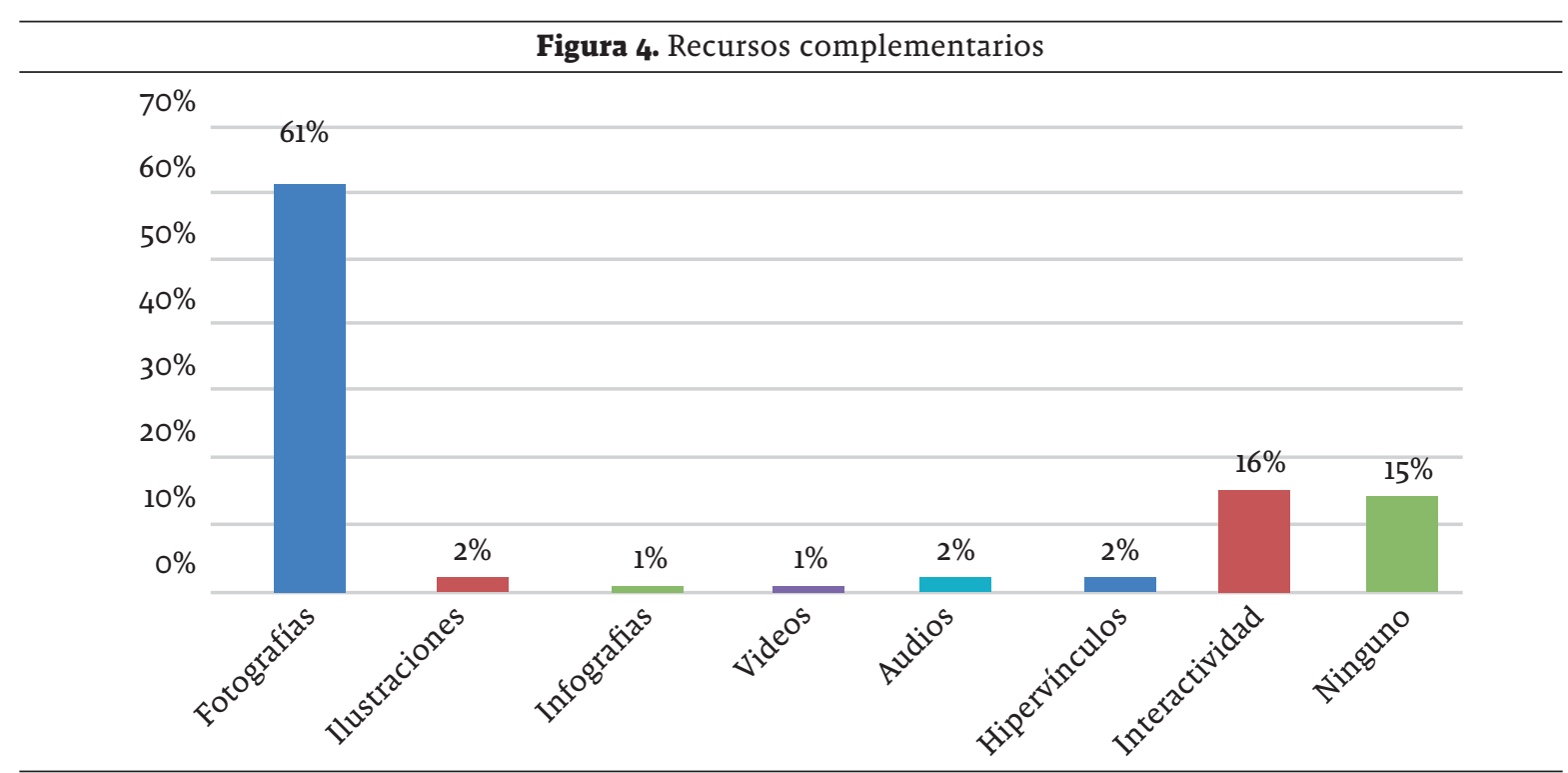

Fuente: elaboración propia. 


\subsection{Tratamiento informativo}

El 68\% de las notas publicadas sobre corrupción, en el período analizado, aparecen sin firma del autor y el 32\% salieron con firma. De las 586 notas registradas, el $71 \%$ fueron textos informativos y el $29 \%$, de opinión.

$\mathrm{Al}$ cruzar los datos, se observa que, mientras el $85,7 \%$ de las notas de opinión aparecen firmadas, tan solo el 10,1\% de los mensajes de géneros informativos llevan firma. Los contenidos de opinión que no llevan firma corresponden principalmente a editoriales, seguidos de columnas con seudónimo y glosas. Por su parte, aunque los reportajes son escasos, como se verá más adelante, un tercio de ellos sí lleva firma, a diferencia de las noticias que aparecen firmadas en menos del $9 \%$ de los casos. Ninguna de las pocas entrevistas publicadas en este período apareció firmada.

La decisión de firmar o no las notas puede estar vinculada a razones relacionadas con la protección a los periodistas que hacen denuncias sobre corrupción, pero al parecer también obedece a decisiones editoriales o de manual de estilo: en los sitios web de El Tiempo Café, RCN Radio y De La Realidad, el 100\% de los contenidos informativos sobre corrupción aparecieron sin firma del autor. En Caracol, el 50\% de las notas informativas son anónimas; en Eje 21, el 99\%; y en La Patria, el 76\%. En cuanto a la opinión, en Eje 21, el 13,9\% de los mensajes son anónimos y, en La Patria, aparecen sin firma el $13,7 \%$ de las opiniones sobre corrupción (ver Figura 5).
En cuanto al análisis por géneros, del total de notas publicadas en el período objeto de análisis, el $64 \%$ corresponden a noticias y el $26 \%$, a columnas de opinión. Al desagregar los datos de las notas informativas y las notas de opinión se observa que, en los géneros informativos, las noticias corresponden al $\mathbf{9 2} \%$ de las publicaciones. El $7 \%$ son reportajes y el $1 \%$, entrevistas. Durante los seis meses de análisis, ninguno de los seis medios observados publicó crónicas sobre temas de corrupción. Por su parte, entre las notas de opinión, el $87 \%$ fueron columnas; el $11 \%$, editoriales; el $1 \%$, glosas, breves o bocadillos; y el $2 \%$, otros géneros, principalmente réplicas. Los resultados se presentan en la Figura 6.

De los seis medios observados, los "otros géneros" distintos de las noticias y las columnas de opinión se concentran básicamente en el periódico La Patria, que publicó el $87 \%$ de los reportajes sobre corrupción publicados, en este período. Eje 21 publicó el $10 \%$ y el 3\% restante apareció en De la realidad. En cuanto a las entrevistas, el 66\% fueron publicadas en La Patria

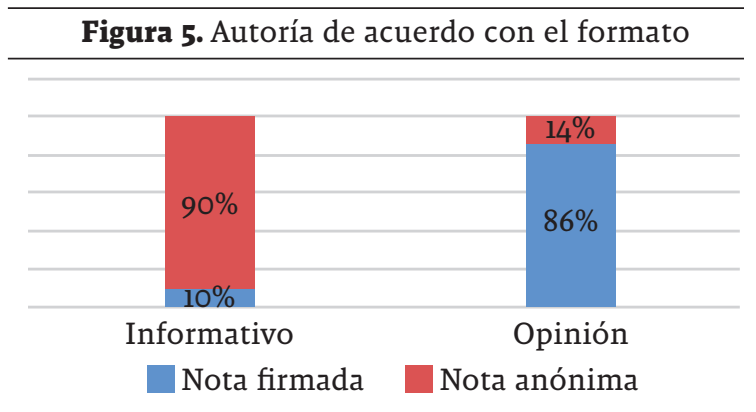

Fuente: elaboración propia.

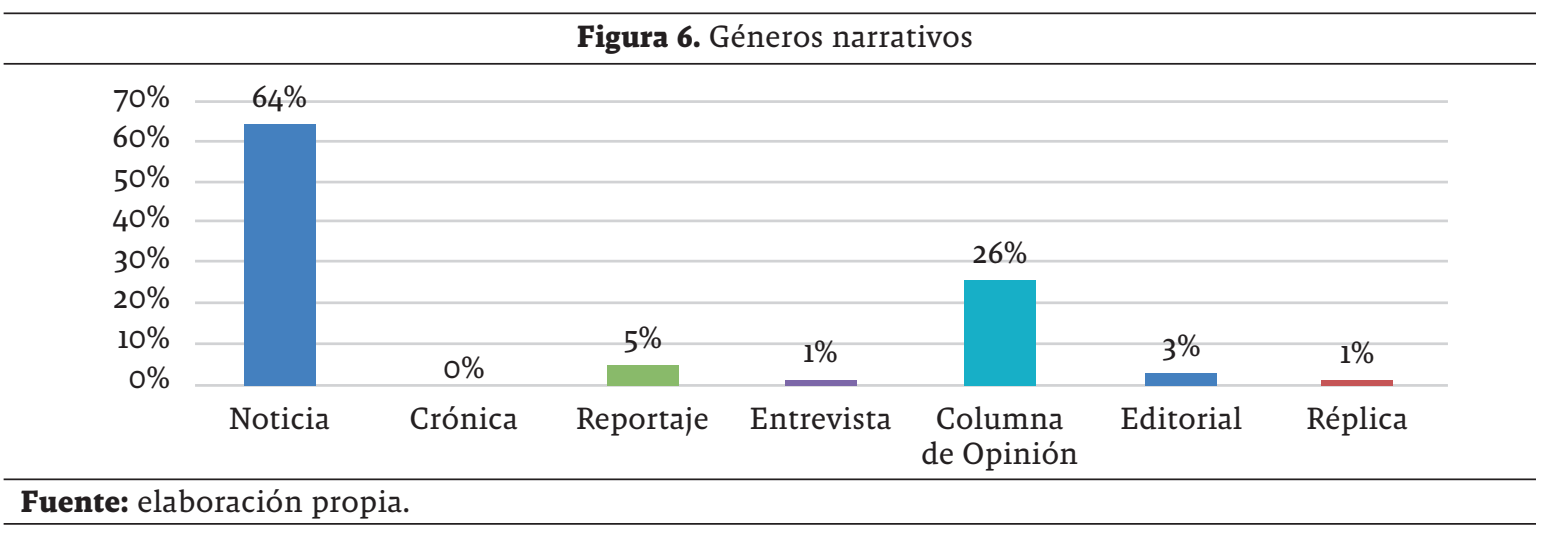


y el 33\% restante, en De la Realidad. En cuanto a los editoriales, el $53 \%$ se publicó en La Patria y el $47 \%$, en Eje 21.

Históricamente, el periodismo de investigación, desde Watergate hasta hoy, ha tenido a la corrupción como uno de sus grandes temas a desarrollar. El periodismo de investigación permite que el medio desarrolle una agenda informativa propia en la que es el periodista, o el equipo de periodistas, el que plantea un tema y lo incluye dentro de la oferta informativa para sus receptores. Sin embargo, del análisis realizado durante seis meses a los medios locales digitales de Manizales, se observa que este tipo de periodismo es muy excepcional: solo el $16 \%$ de las notas publicadas correspondieron a agenda propia, en contraste con un 50\% de publicaciones cuyo origen fue la agenda obligada. Es decir, el cubrimiento rutinario de ruedas de prensa o la publicación de registros de ruedas de prensa. Otro $15 \%$ correspondió a agenda copiada, es decir, la reproducción de cables de agencias de noticias nacionales o internacionales.

El análisis por medios indica que el 63,5\% de las notas de agenda propia fueron publicadas en $\mathrm{La}$ Patria; el 48\% de la agenda obligada apareció en Eje 21; y el 76\% de la agenda copiada, también en Eje 21. Esto significa que -si bien Eje 21 publicó el $48 \%$ de la información sobre corrupción que apareció en el período objeto de este estudio, en los seis medios observados- dicho volumen no necesariamente implica calidad de la información, ya que es el medio que mayor cantidad de agenda obligada y copiada registra. La agenda personal, que corresponde al interés particular de un opinador por un tema específico -por fuera de la agenda de coyuntura del momento- se reparte en un 54\%, en La Patria y un $43 \%$, en Eje 21 .

Con relación a los géneros, se observa que el $56 \%$ de los textos de agenda propia corresponden a reportajes y el $28 \%$, a noticias. La agenda obligada corresponde, en un $95 \%$, a noticias. Se trata de una proporción similar a la de agenda copiada, que alcanza el $92 \%$ en el formato de noticia. Por su parte, la agenda personal se encuentra principalmente en columnas de opinión, con un $87 \%$, y el resto se refleja en editoriales. Los resultados se presentan en la Figura 7.

Del total de 586 publicaciones registradas sobre corrupción para este análisis, $66 \%$ tuvieron connotación negativa y $34 \%$, connotación positiva. Las notas con connotación negativa se construyeron en distintos tipos de formatos: el $52 \%$ en noticias, el $34,8 \%$ en columnas de opinión, el $7,2 \%$ en reportajes y el $4 \%$ en editoriales. En contraste, las notas de connotación positiva corresponden en un $87,8 \%$ a noticias y un $6,3 \%$ a columnas de opinión. La connotación positiva sobre la corrupción en los reportajes, editoriales, glosas y entrevistas es casi inexistente.

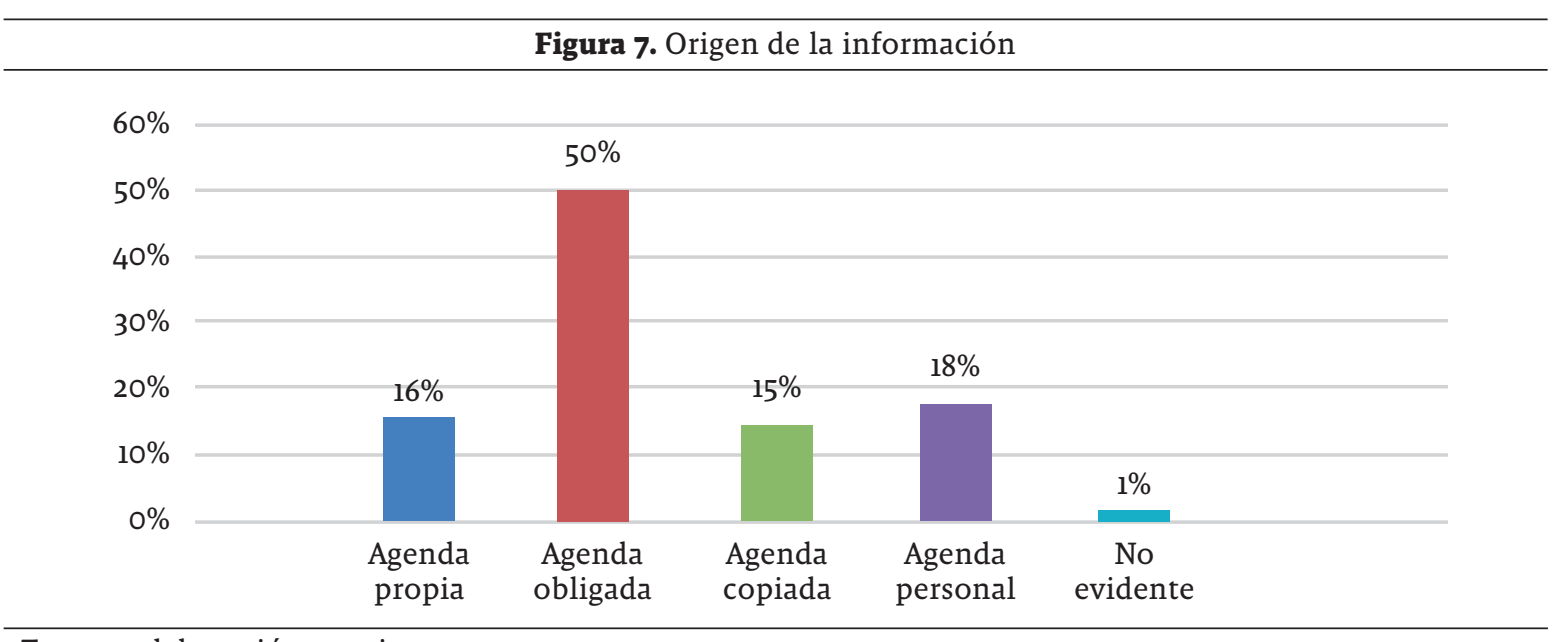

Fuente: elaboración propia. 
El análisis por medios arroja que, en relación con el total de notas publicadas por cada uno de ellos, solo en De la Realidad la mayoría de las notas son positivas, con un porcentaje del $62 \%$. Por su parte, La Patria registra el porcentaje más bajo de notas sobre corrupción con connotación positiva, con un $23,3 \%$ del total de sus publicaciones. En RCN, el total de notas positivas fue del $43 \%$ y, en los demás medios, se ubicó entre el 30 y el $35 \%$. Los resultados se presentan en la Figura 8.

Con relación al manejo de fuentes, se observa que el 68\% de las notas cita fuentes de información y el $32 \%$ no cita ninguna. Entre los que no citan fuentes, el $64 \%$ corresponden a columnas de opinión; el $9 \%$, a editoriales y el $25 \%$, a noticias. Las noticias sobre temas de corrupción que no citan fuentes se ubican, en un 46,8\%, en Eje 21. Los demás medios aportan entre el $10 \%$ y el $14 \%$ de las noticias sin fuentes, salvo el diario El Tiempo, que no registra ninguna publicación sin mención de su fuente de información. Los resultados se presentan en la Figura 9.

De las notas que sí mencionan fuentes, el $63 \%$ cita una; el $22 \%$ cita dos; el $8 \%$ alude a tres fuentes de información; el $4 \%$, a cuatro; y otro $4 \%$, a cinco o más. Al desagregar los datos por géneros se observa que, del total de noticias que tienen fuentes, el $67,5 \%$ incluye solo una, mientras que en los reportajes el número de fuentes tiende a ser mayor: el $20 \%$ cita solo a una; el $20 \%$, a tres y el $34,4 \%$, a cinco o más. En cuanto a los géneros de opinión, en las glosas o bocadillos no se encontraron fuentes de información; en los editoriales no aparecieron más de dos fuentes, mientras que en las columnas de opinión, que sí mencionan fuentes, el $48 \%$ incluye solo una, el $33 \%$ cita dos, el $7 \%$, a tres, y otro $7 \%$, a cuatro.

Al desagregar los datos de las notas que sí citan fuente, se observa que La Patria es el único medio en el que las notas con solo una fuente son inferiores al 50\% y es, además, el único que registra publicaciones con cuatro o más fuentes citadas. En los demás medios, las publicaciones que mencionan fuentes incluyen solo una proporción que oscila entre el $55 \%$ y el $80 \%$ de las publicaciones, y la inclusión de una segunda fuente solo llega al $25 \%$ de las notas.

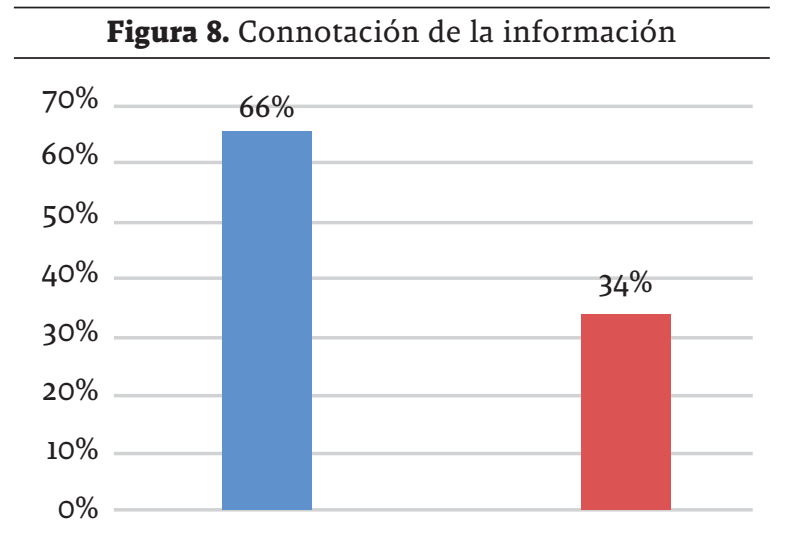

Connotación negativa Connotación positiva

Fuente: elaboración propia.

Figura 9. Mención de fuentes

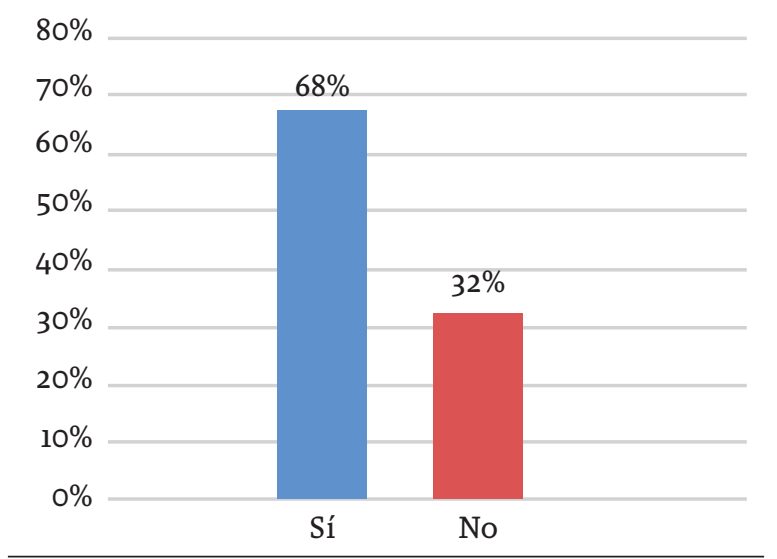

Fuente: elaboración propia.

A medida que aumentan el número de fuentes citadas, la connotación de la información sobre corrupción tiende a volverse negativa: mientras en las noticias que citan una sola fuente el $44 \%$ tiene connotación negativa, en las que citan dos, el porcentaje baja al 35\%. En las que citan tres, el porcentaje de notas negativas se ubica en el $10 \%$; y en las que citan cuatro fuentes la connotación positiva cae al $7 \%$. Los resultados de este apartado se presentan en la Figura 10.

Con relación a los tipos de fuentes citadas por los medios para hablar de corrupción, el $50 \%$ se concentra en el poder ejecutivo, político (Con- 


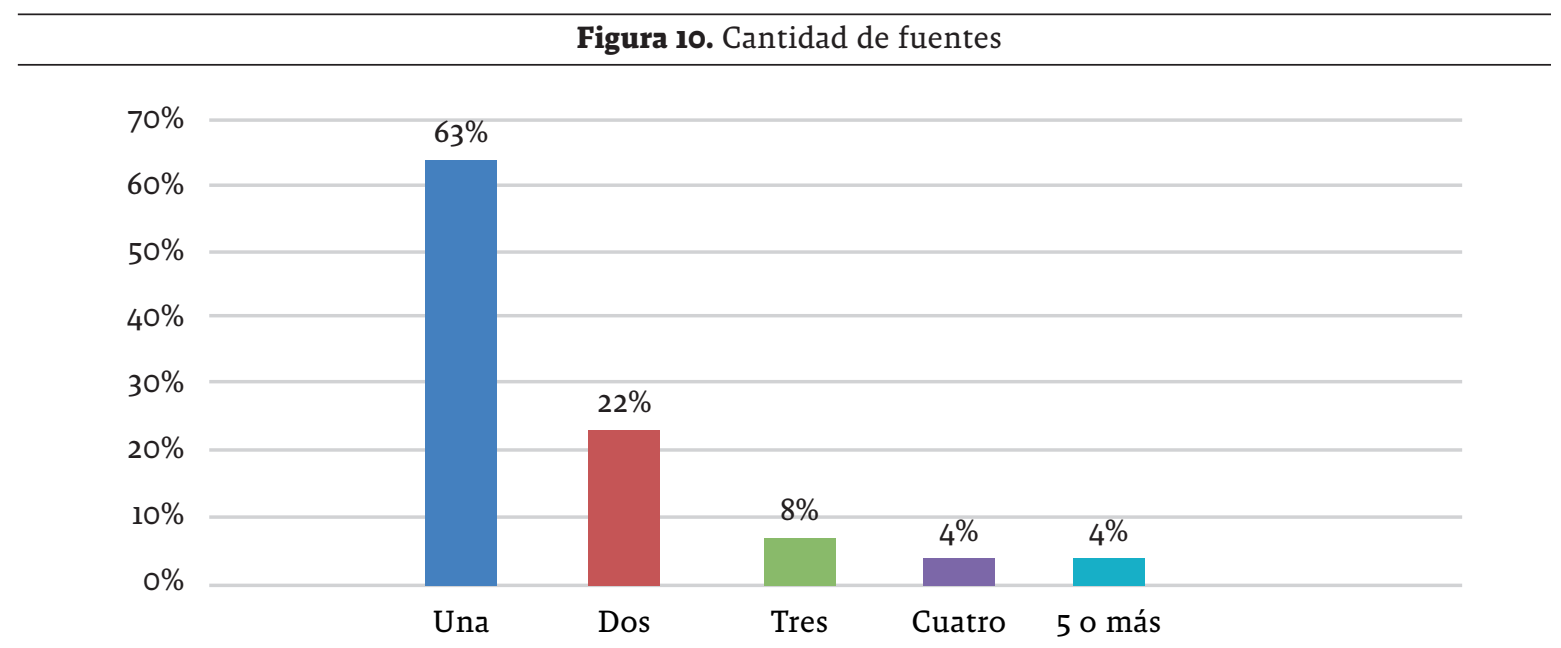

Fuente: elaboración propia.

greso, Asambleas y Concejos) y judicial. Los órganos de control como contralorías, Procuraduría y personerías, en quienes recae el rol de controlar la corrupción estatal, corresponden al $8 \%$ de las fuentes citadas. Los ciudadanos que hablan a título particular son el 10\% de las fuentes, mientras que la sociedad civil organizada en veedurías y ONG corresponde al 5\%. El 10\% de las fuentes son empresarios y miembros del sector privado; el 6\%, periodistas (reporteros o líderes de opinión que denuncian casos de corrupción y se convierten en fuente informativa de otros medios); y el $3 \%$ restante son voces de la academia.

El tipo de fuente citada incide en la connotación de la información: el 50\% de las publicaciones que mencionan a los órganos de control, el $42 \%$ de las que mencionan al poder ejecutivo y el $40 \%$ de las que citan al poder judicial, tienen connotación positiva, con una retórica que incluye mensajes como "estamos cumpliendo", "estamos luchando contra la corrupción" o "estamos adoptando medidas". En contraste, tan solo el $17,5 \%$ de las notas que cita al poder político como fuente de la información tiene connotación positiva. Esto se explica porque en numerosos casos se trata de informaciones con más de una fuente, en las que el político aparece defendiéndose de acusaciones sobre corrupción entregadas por otra fuente.
Las notas que incluyen fuentes de información alternativas tienen una connotación de la corrupción que tiende a ser negativa: alcanza el $82 \%$ en las publicaciones que incluyen voces de empresarios y sector privado; el $81 \%$ en las que mencionan a la sociedad civil organizada; el $80,6 \%$ en las que usan como fuente otros medios o periodistas; el $72,7 \%$ en las que incluyen voces de ciudadanos particulares; y el $70,5 \%$ en las que aparecen voces de la academia.

Todos los medios analizados incluyen fuentes del sector público, pero la participación de otras voces varía de acuerdo con los medios. El 80\% de las notas que citan a otros medios o periodistas como fuente se concentra en Eje 21. Por su parte, el $82 \%$ de las publicaciones que tienen como fuente a la academia están en La Patria, medio en el que aparecen el $64 \%$ de las voces del sector privado, el $55 \%$ de las fuentes que corresponden a sociedad civil organizada y el $43 \%$ de los ciudadanos que hablan a título personal. En Eje 21, están el $48 \%$ de las publicaciones que citan al poder ejecutivo, el $45 \%$ de las que mencionan al poder político, el $57 \%$ de las que tienen como fuente al poder judicial y el $61 \%$ de las notas que incluyen como fuente a los órganos de control. Los resultados se presentan en la Figura 11.

Aunque este estudio incluyó 576 publicaciones que se refieren a asuntos de corrupción, el 57\% 


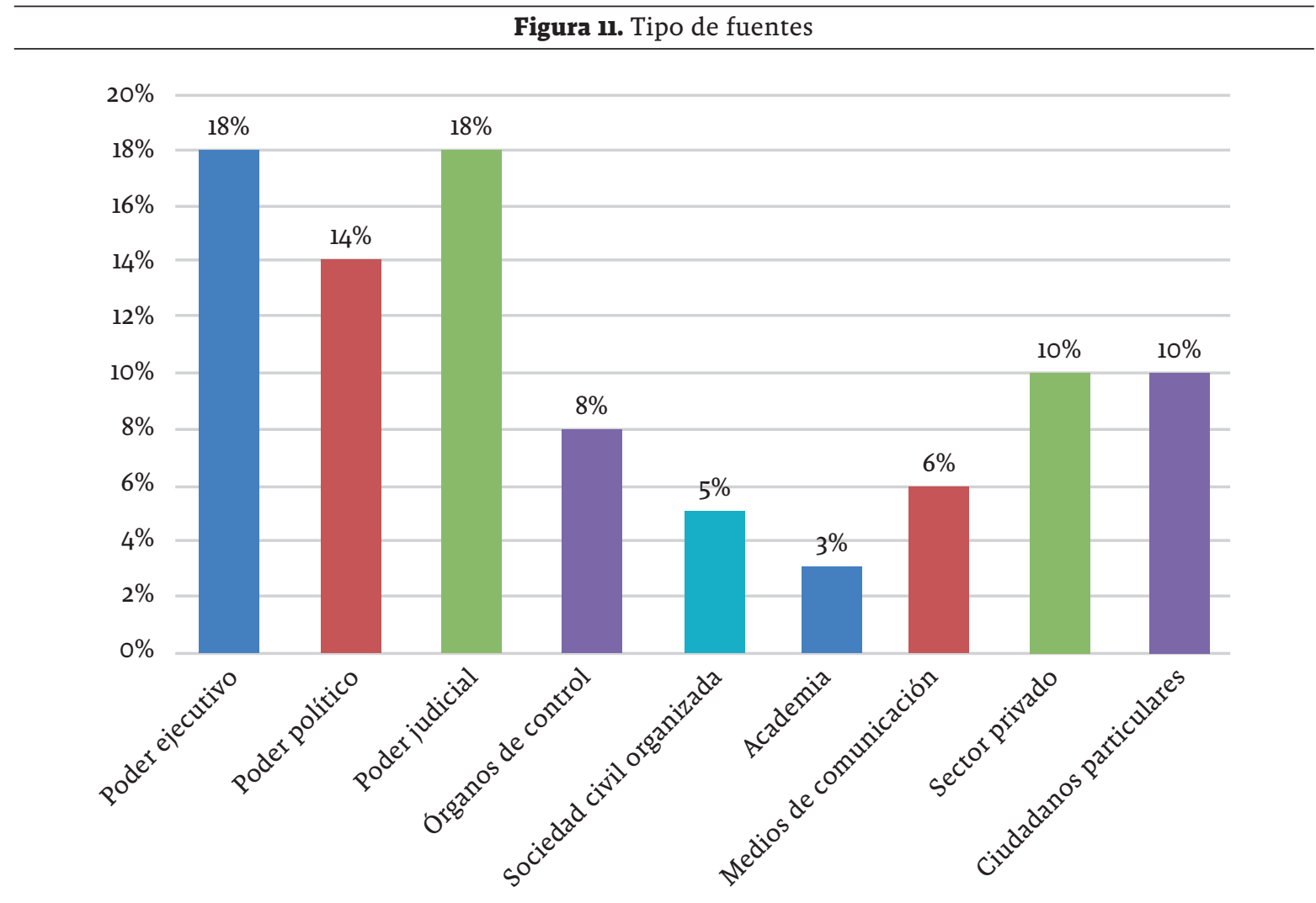

Fuente: elaboración propia.

de ellas no incluye la palabra "corrupción", vocablo que es un sustantivo pero que, por el uso que se le da o, mejor aún, por su falta de uso, al parecer se asume como un adjetivo, en la medida en que califica una acción: decir que hay un acto de corrupción, utilizando dicho vocablo, implica para el periodista una carga valorativa. Mientras que el $72,9 \%$ de los textos de opinión sobre corrupción sí menciona explícitamente la palabra "corrupción", tan solo el 30,6\% de los textos informativos lo hace.

Esta es una característica común en los seis medios analizados. Al desagregar los datos sobre notas informativas y excluir las de opinión, se observa que el vocablo "corrupción" aparece entre el $15 \%$ y el $38 \%$ de los artículos informativos, siendo El Tiempo y Caracol los que menos lo utilizan, seguidos de La Patria, mientras que su uso es más frecuente en los medios virtuales sin soporte en otro formato, como De La Realidad y Eje 21.
Existe una relación entre el número de fuentes a citar y la mención explícita del vocablo "corrupción". Entre los textos de carácter informativo (noticias, reportajes, entrevistas) que sí citan fuentes, la palabra corrupción aparece en el 31,6\% de las publicaciones, mientras que en aquellos que no citan fuentes la mención del vocablo cae al $23 \%$ de las notas. Esto se explica porque con frecuencia la palabra corrupción, que aparece en los textos informativos, corresponde a una cita entrecomillada de alguna fuente y no a una afirmación del periodista. Los resultados se presentan en la Figura 12.

Se observa una leve relación entre la mención de la palabra "corrupción" y la mención específica de conductas punibles dentro de las publicaciones. Mientras que el promedio general de notas que incluye la palabra "corrupción" es del $38 \%$, entre las notas que mencionan delitos ese promedio sube al $42 \%$. 


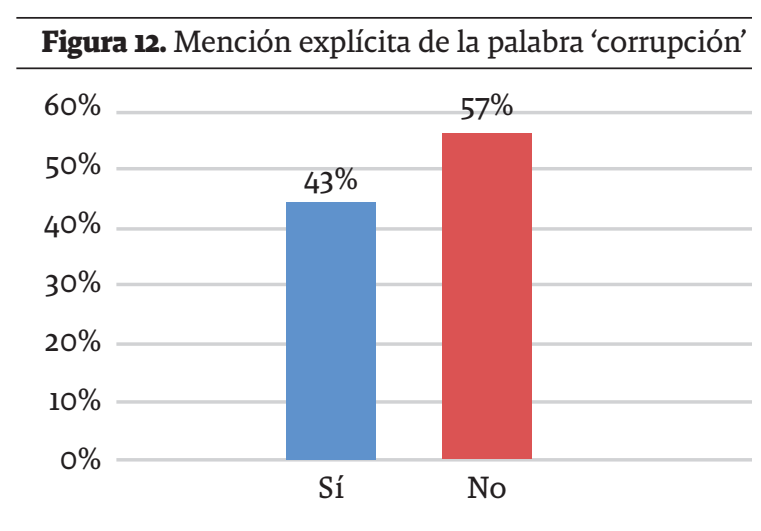

Fuente: elaboración propia.

Aunque el código penal colombiano tipifica más de 15 delitos contra la administración pública, las conductas punibles que se mencionan en las notas analizadas se concentran básicamente en ocho tipos penales: celebración indebida de contratos (en $8,4 \%$ de las notas que incluyen referencia explícita a algún delito), concierto para delinquir $(6,3 \%)$, falsedad $(5,4 \%)$, peculado $(5,1 \%)$, cohecho $(4,8 \%)$, enriquecimiento ilícito $(4,56 \%)$, estafa $(3,3 \%)$ y tráfico de influencias (3,3\%). También aparecen mencionados, en menor medida, otros delitos como prevaricado, abuso de confianza, testaferrato, concusión, usurpación y abuso de funciones públicas, fraude procesal, manipulación de acciones, tráfico y porte de estupefacientes, lavado de activos, extorsión e interceptación de comunicaciones.

Mientras la inclusión del vocablo "corrupción" es más frecuente en las notas de opinión que en las informativas, la inclusión explícita de delitos es más recurrente en los contenidos informativos. Del promedio de notas analizadas, el $38 \%$ menciona delitos, pero si se desagregan los datos, se observa que solo lo hacen el $28 \%$ de las publicaciones de formato de opinión, como columnas, editoriales y glosas, mientras que su aparición en los formatos informativos se da en el $42 \%$ de las notas.

El 47,3\% de los editoriales publicados sobre corrupción, durante el período observado, mencionaron delitos específicos, siendo este el género que con mayor frecuencia registra esta caracte- rística. Le siguen las noticias, con el $44,7 \%$ y las entrevistas con el $33 \%$. Curiosamente los reportajes, que son los que utilizan mayor número de fuentes y tienen un promedio de palabras mayor, son los textos que menos inclusión de delitos registran: solo el 22,6\% incluye alguna alusión específica a un tipo penal. Esto se explica porque los principales reportajes, publicados durante este período, correspondieron a la agenda propia desarrollada por el diario La Patria sobre dos temas específicos: posible corrupción en la Universidad de Caldas, en la asignación de becas "Andrés Bello" a mejores promedios académicos y la serie "Lupa a la contratación", que periódicamente muestra la forma en la que se está contratando en distintas entidades de la $\mathrm{Al}$ caldía y la Gobernación. En ambos casos, los reportajes describen los hechos que al momento de la publicación no están siendo investigados por las autoridades y, en el caso de la mención de delitos, ocurre algo similar a la mención de la palabra "corrupción": su inclusión en los relatos periodísticos aparece normalmente atribuida a una declaración de una fuente y no a la interpretación del autor de la nota. Los resultados se presentan en la Figura 13.

Con relación a la proximidad geográfica entre el sitio de publicación y el lugar de los hechos, se observa que dos terceras partes de los contenidos relacionados con corrupción, publicados por medios digitales locales, se refieren a hechos ocurridos por fuera del ámbito local.

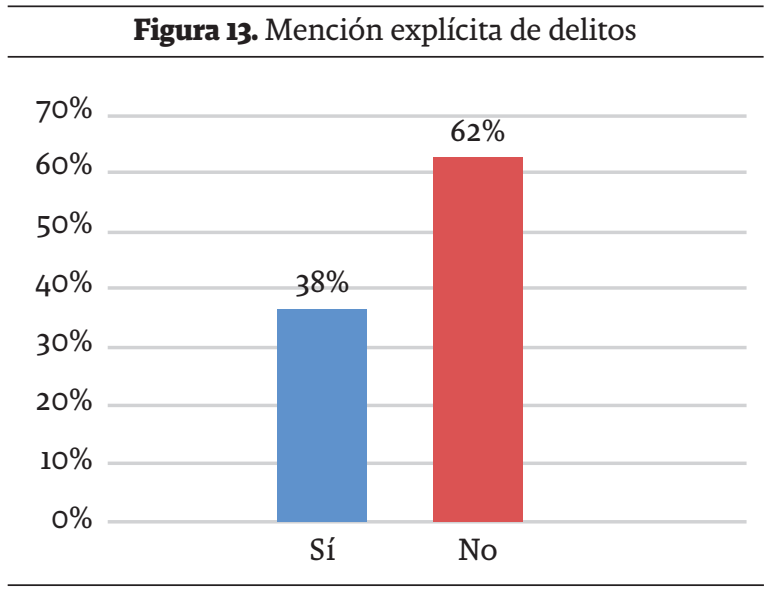

Fuente: elaboración propia. 
Del total de notas publicadas sobre corrupción en los medios locales digitales de Manizales, el $47 \%$ alude a hechos de corrupción nacional; el $13 \%$, regional; el $7 \%$, internacional; y el $33 \%$, local. Por formato, las variaciones en esta relación son leves: la alusión a corrupción regional y nacional tiende a ser un poco superior en los textos de opinión, mientras que la referencia a corrupción local e internacional es levemente superior en los contenidos de carácter informativo. En ninguno de los casos, la variación supera los 3 puntos porcentuales.

La connotación de la información tiende a ser ligeramente más positiva en los contenidos sobre corrupción local, en donde el promedio de textos positivos se ubica dos puntos por encima del promedio. Mientras que en los asuntos relacionados con corrupción nacional, la connotación negativa desciende 3 puntos por debajo del promedio.

El 48\% de las publicaciones sobre corrupción local tienen su origen en agenda obligada. La agenda propia alcanza el $24 \%$ de los contenidos sobre corrupción local. No obstante, se observa que del total de publicaciones que tienen origen en agenda propia, el $50 \%$ se concentra en corrupción local y otro $15 \%$, en corrupción regional.

Se observa, además, que en los temas de corrupción internacional el número de notas que no citan fuentes está 10 puntos por debajo del promedio. Mientras que en los de corrupción local, los textos sin fuentes están 5 puntos por encima del promedio. En el caso de la corrupción local, los textos sin fuentes son un punto inferior al promedio y, en los de corrupción nacional, no hay variación con relación al promedio.

Del total de notas sobre corrupción local publicadas, durante el período, el $47 \%$ apareció en $\mathrm{La}$ Patria. No obstante, al comparar los contenidos sobre corrupción local con el total de contenidos sobre corrupción publicados por cada medio, se observan diferencias: en los medios digitales con soporte en emisoras (Caracol y RCN) la publicación de contenidos sobre corrupción gira en torno a asuntos locales, en un promedio que oscila entre el $62 \%$ y el $71 \%$ de su agenda informativa sobre este tema. Por su parte, en los medios exclusivamente digitales (De la realidad y Eje 21), la corrupción local ocupa entre el $20,6 \%$ y el $22 \%$ de su agenda informativa sobre corrupción. En los medios digitales con soporte en impresos (La Patria y El Tiempo), la agenda local sobre corrupción concentra entre el $47 \%$ y el $60 \%$ de las publicaciones sobre este tema. Los resultados sobre el apartado se presentan en la Figura 14 .

Así como los medios locales digitales tienden a publicar asuntos sobre corrupción ocurridos en

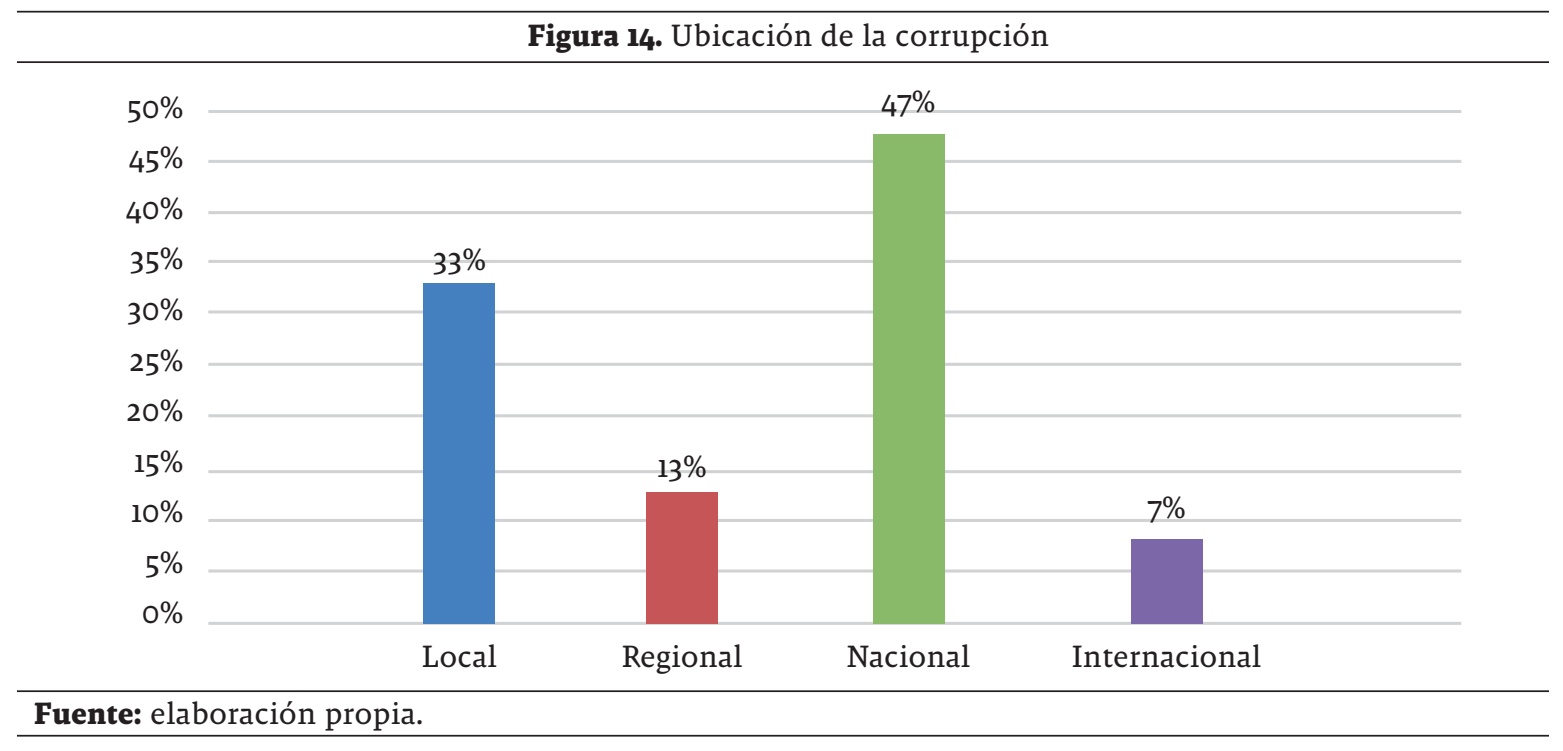


ámbitos por fuera del plano local, se observa que los hechos referidos tienen relación con el pasado y no con el presente: el $32 \%$ de las publicaciones se refiere a hechos ocurridos hace más de 5 años; el $25 \%$, a situaciones que ocurrieron entre l y 5 años atrás; $30 \%$ de las publicaciones alude a hechos de corrupción ocurridos entre un mes y 12 meses antes de la publicación; y solo el $12 \%$ se refiere a hechos ocurridos en las últimas 4 semanas.

Se observa que hay una relación directa entre proximidad temporal y proximidad geográfica: del total de publicaciones referidas a hechos de corrupción inmediatos (ocurridos en las últimas 4 semanas), el $53,4 \%$ son temas locales y el $34,2 \%$, temas nacionales. Por su parte, del total de publicaciones sobre hechos de corrupción internacional, el $64,7 \%$ se refiere a hechos ocurridos hace más de 5 años.

Las notas con connotación positiva tienden a ser un poco más frecuentes en los relatos sobre corrupción inmediatos u ocurridos hace menos de un año. Mientras que la connotación negativa se ubica 10 puntos porcentuales por encima del promedio en los hechos ocurridos hace un lustro o más.

Algo similar ocurre con la relación entre el origen de la agenda y la inmediatez de la informa- ción: si bien las publicaciones sobre corrupción inmediata ocupan el $12 \%$ de la agenda informativa sobre corrupción, cuando el origen de la información es agenda propia, el promedio se eleva al $14 \%$. La agenda personal, que tiene prevalencia principalmente en textos de opinión, da origen al $51 \%$ de las publicaciones sobre hechos de corrupción ocurridos hace más de un lustro. Los resultados se presentan en la Figura 15.

Así como el $58 \%$ de las fuentes que se utilizan para hablar de corrupción corresponden a voces del sector público, del total de publicaciones sobre corrupción, el $47 \%$ se refiere a corrupción política; el 22\%, a asuntos relacionados con infraestructura; el 19\%, a temas de economía; y las publicaciones restantes versan sobre corrupción en salud, educación, cultura, academia y otros ámbitos.

Como ya se mencionó, entre el poder ejecutivo, el político y el judicial se concentran el $50 \%$ de las voces que hablan sobre corrupción. Estas voces se refieren principalmente a asuntos de corrupción política, infraestructura y economía, en ese orden. Durante el período analizado, no se encontraron publicaciones que incluyeran como fuentes a congresistas, diputados o concejales, que se refirieran a asuntos de corrupción en los sectores de educación, academia, salud o

Figura 15. Temporalidad de la corrupción

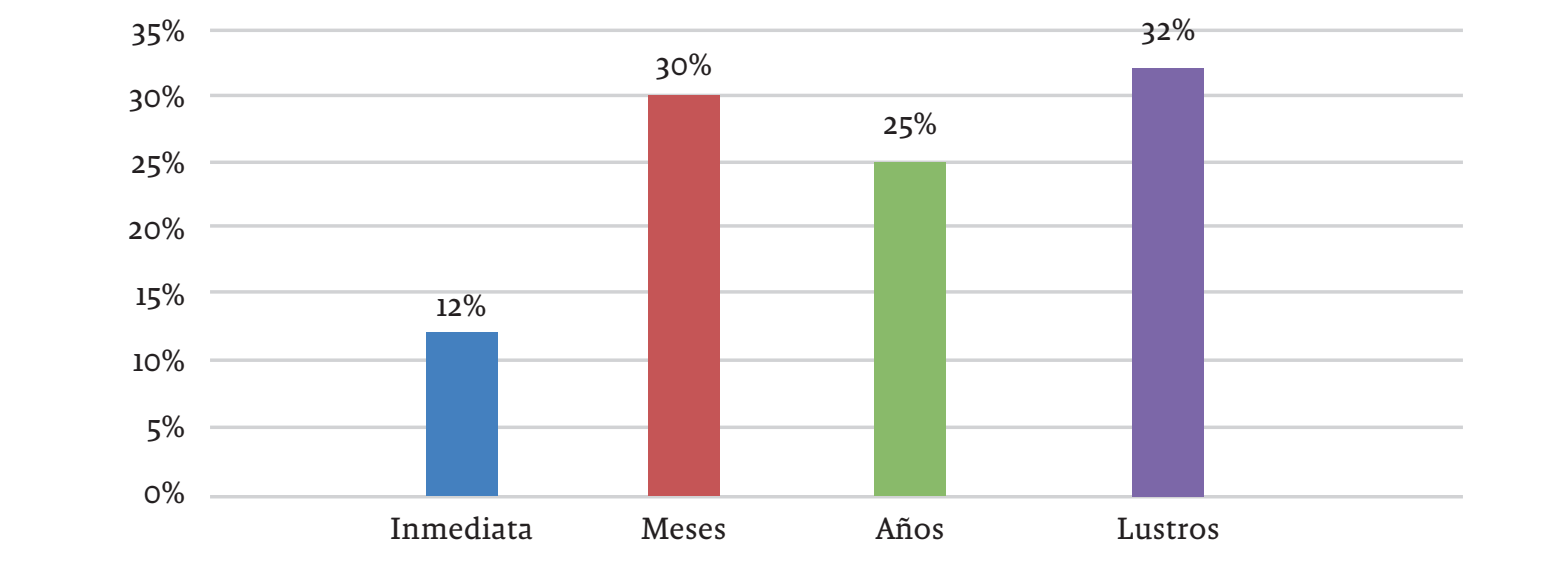

Fuente: elaboración propia. 
cultura. Lo cual coincide con el análisis hecho sobre la connotación de la información: cuando los políticos hablan sobre corrupción en los medios, usualmente lo hacen para defenderse de las acusaciones que les han hecho otras voces, sobre corrupción política.

Aunque la agenda sobre corrupción está fuertemente concentrada en el ámbito político -con el $47 \%$ de las publicaciones-, se observa que las fuentes alternativas, como sociedad civil organizada, ciudadanos particulares, sector privado y medios de comunicación, tienden a referirse también a otros ámbitos de la corrupción, como cultura, educación y salud. Mientras que las fuentes del sector público se enfocan en corrupción política e infraestructura.

Durante el período objeto de análisis, ninguna voz del sector judicial se refirió a hechos de corrupción en el sector de la educación; de igual manera, ningún miembro de los órganos de control habló sobre corrupción en el sector de la cultura y ningún miembro de la academia apareció como fuente informativa en los medios hablando de corrupción. Los resultados se presentan en la Figura 16.

De acuerdo con lo explicado en el marco teórico sobre la tipología de la corrupción por colores, se observa que el $52 \%$ de las publicaciones incluye una visión negra de la corrupción, el 37\%, una referencia gris y el $11 \%$ alude a corrupción blanca.

La corrupción negra aparece con mayor incidencia en los textos de opinión que en los informativos, mientras que la corrupción gris tiene mayor prevalencia en los contenidos informativos que en los de opinión. La corrupción blanca no presenta variaciones significativas con relación al formato narrativo.

Se observa una relación directa entre el color de la corrupción y la proximidad geográfica de los hechos: a mayor distancia la corrupción se oscurece. Así, mientras el 38,4\% de las notas sobre corrupción local es negra, el $42 \%$ es gris, y el 19,4\%

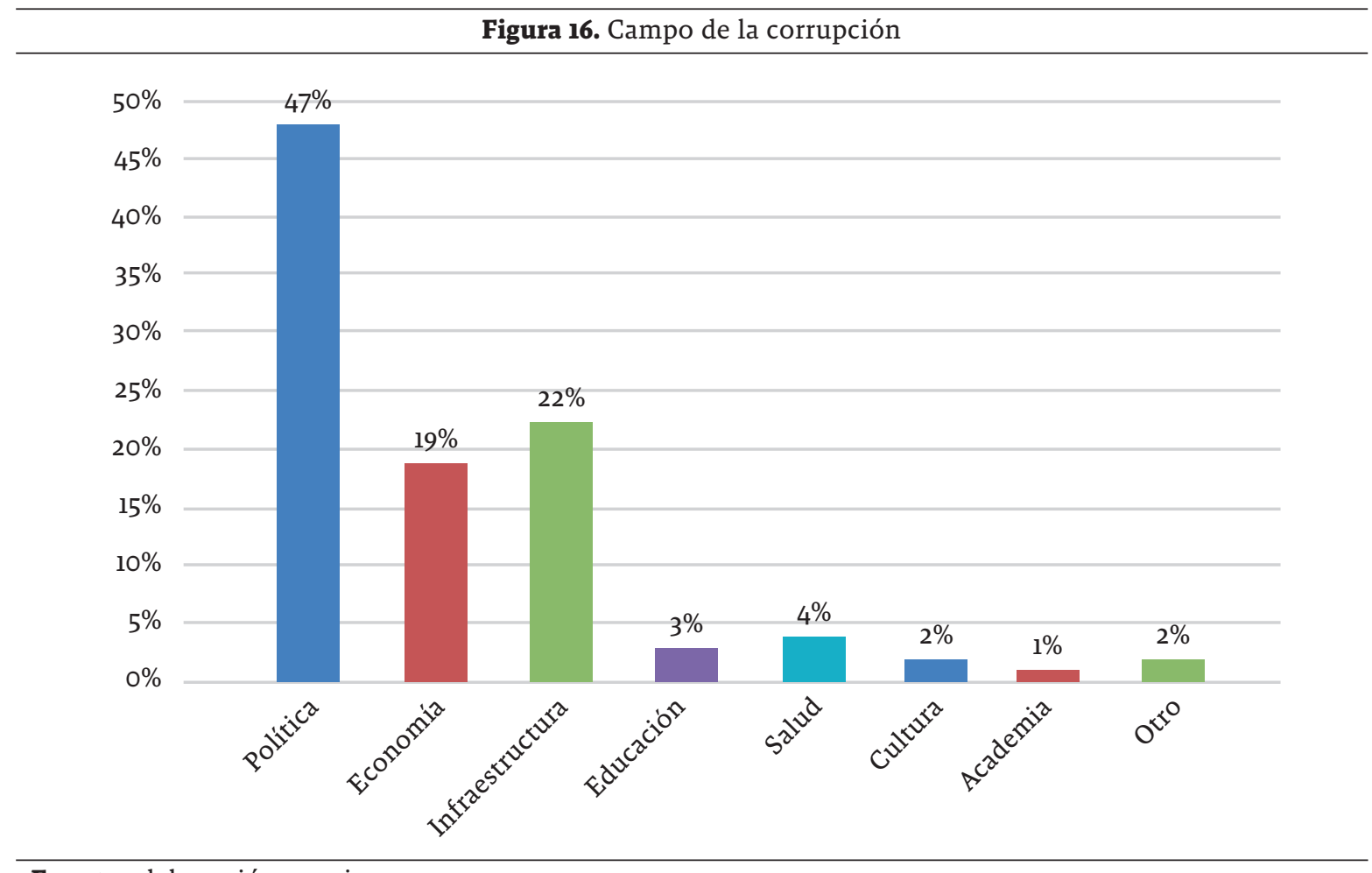

Fuente: elaboración propia. 
es blanca. Estos porcentajes tienden a invertirse a medida que la corrupción se aleja: los contenidos sobre corrupción regional se presentan como corrupción negra en un $64 \%$ de los casos, frente a un $24,2 \%$ de corrupción gris y un $12 \%$ de corrupción blanca. En el caso de la corrupción nacional, la relación es de $64,2 \%$ de corrupción negra, a $29,7 \%$ de corrupción gris y $6 \%$ de corrupción blanca; y la internacional es un $75 \%$ negra, un $23,1 \%$ gris y un $2 \%$ blanca.

La misma tendencia se observa con relación a la temporalidad del hecho narrado: mientras en los textos que se refieren a corrupción inmediata, ocurrida hace un mes o menos, el $23,8 \%$ se presenta negra; el $46 \%$, gris; y el $30 \%$, blanca, la tendencia comienza a invertirse a medida que la ocurrencia del hecho se aleja en el tiempo, hasta llegar a un 73,3\% de corrupción negra, en hechos ocurridos hace un lustro o más. En comparación con un $37 \%$ de corrupción gris y un $10 \%$ de corrupción blanca. Los resultados se presentan en la Figura 17.

Con relación a la representación de la corrupción, el $48 \%$ de las publicaciones la muestran como una práctica ilegal; el $17 \%$, como un comportamiento antiético; el $15 \%$, como decadencia invasiva; y el $9 \%$, como una irregularidad.

La representación de la corrupción como decadencia invasiva es propia de los géneros de opinión: del total de publicaciones que incluyen esta visión, el 75,5\% son columnas de opinión y editoriales. Por su parte, la corrupción

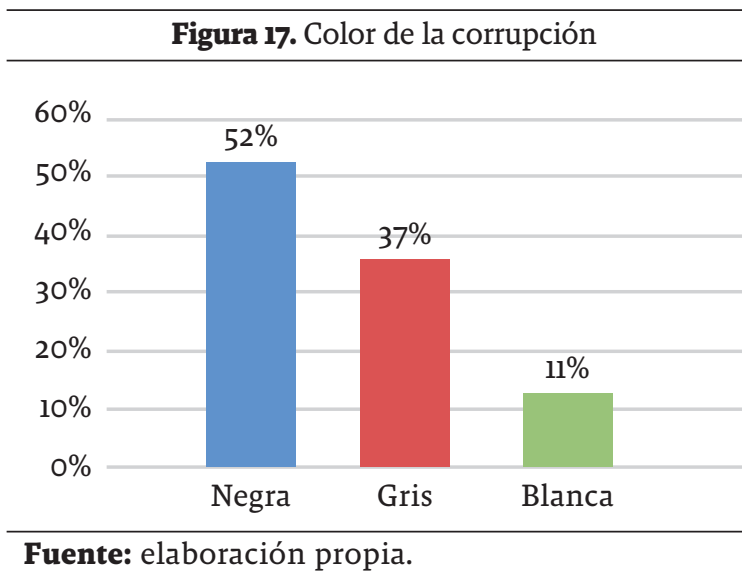

como práctica ilegal aparece en un $80,8 \%$ en textos informativos. El 74,6\% de alusiones a la corrupción, como comportamiento antiético, se registra en contenidos informativos, y el 60,9\% de las representaciones de la corrupción, como acciones irregulares, se ubican en géneros informativos.

Aunque las publicaciones con connotación positiva representan un tercio del total de contenidos alusivos a la corrupción, se observa que entre estas el $67,3 \%$ representa la corrupción como una práctica ilegal. En todos los cruces de datos efectuados se observa que, al representar la corrupción como una ilegalidad, la connotación positiva de la publicación se eleva. Así mismo, las notas que representan la corrupción como práctica ilegal tienen menciones explícitas de la palabra "corrupción", 10 puntos por debajo del promedio, mientras que las publicaciones que presentan la corrupción como práctica invasiva, incluyen la palabra "corrupción" 11 puntos por encima del promedio. En el caso de las publicaciones que se refieren a la corrupción como comportamiento antiético y como acción irregular, la mención de la palabra "corrupción" no registra incidencia significativa.

Por su parte, no se observan variaciones muy significativas entre la representación de la corrupción y la mención específica de delitos. Las publicaciones que sí mencionan delitos tienden a ser un poco menos frecuentes en las representaciones de la corrupción como acción irregular y un poco más frecuentes en las demás representaciones. Pero, en ningún caso, la variación supera los 3 puntos porcentuales. Los resultados se presentan en la Figura 18.

\section{Conclusiones}

La pregunta inicial de la investigación: ¿cómo comunican los temas y hechos de corrupción los medios de comunicación digitales de Manizales? Tiene varias formas de responderse.

En primer lugar, habría que señalar que existe una diferencia significativa entre la información y la opinión sobre hechos de corrupción, que se refleja 


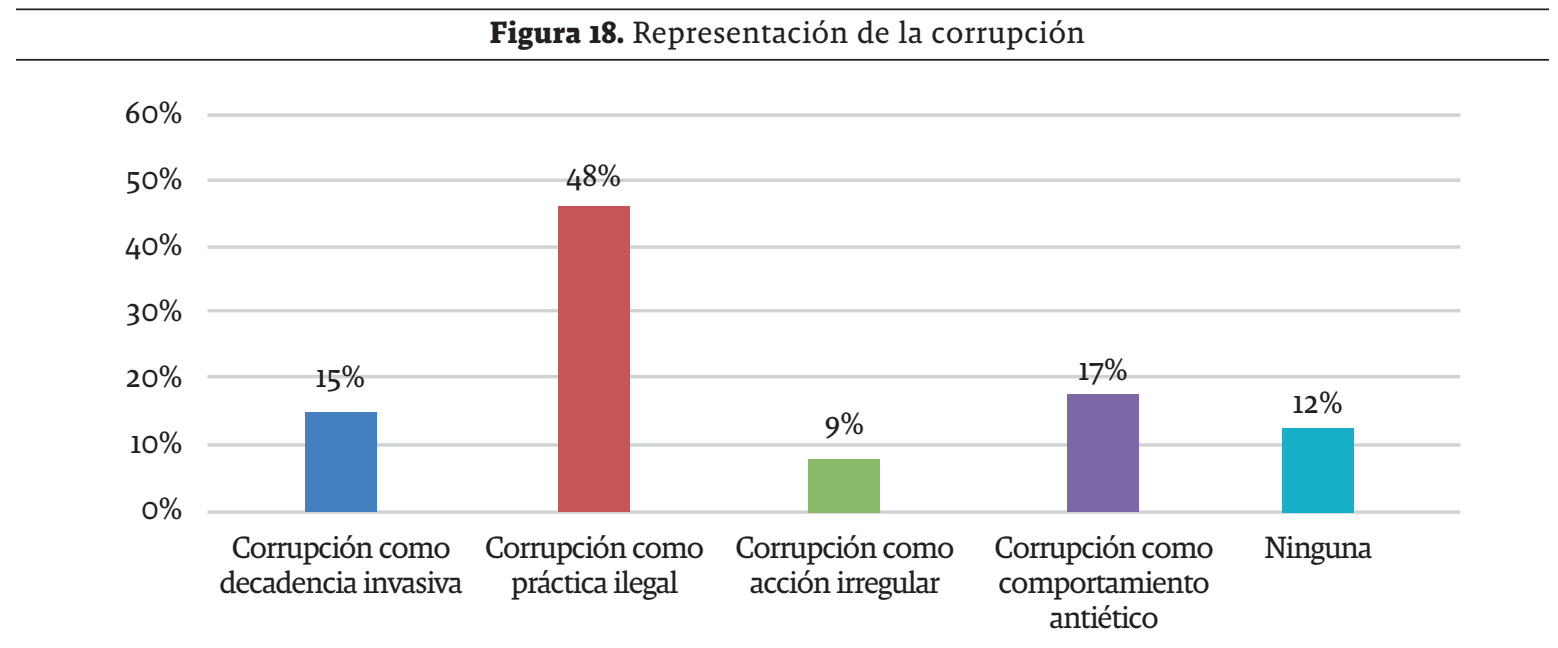

Fuente: elaboración propia.

en connotación, fuentes, temporalidad, color y representación, entre otros aspectos.

Aunque el estudio se concentró en medios locales digitales, es notorio que la mayoría de los contenidos de corrupción se refieren a hechos nacionales, más que a asuntos locales, y a hechos ocurridos hace meses, años o lustros, más que a asuntos recientes. La investigación periodística sobre corrupción, que se refleja en agenda propia, cantidad y variedad de tipos de fuentes, se concentra principalmente en La Patria, uno de los seis medios observados.

La selección de fuentes marca el enfoque de la información: la connotación tiende a ser positiva con las fuentes oficiales, y negativa con fuentes alternativas como ciudadanía organizada, ciudadanos particulares, voces de la academia y otros. Así mismo, las fuentes alternativas tienen una agenda sobre la corrupción que incluye ámbitos como la academia, la salud, la educación y la cultura, mientras que las voces oficiales tienden a hablar de corrupción política, infraestructura y economía.

Como se referenció al comienzo, la corrupción es percibida por un número significativo de colombianos como el principal problema del país. Esto se refleja en la presencia constante del tema en la agenda informativa de los medios locales. Pero se observa, así mismo, que la cantidad de notas publicadas no necesariamente da cuenta, de manera exclusiva, del problema y responden más a eventos ocasionales que entran en la agenda obligada de los medios. Un tercio de las publicaciones consiste en espacios en los que voceros oficiales informan sobre su trabajo de lucha contra la corrupción. Ese trabajo no se refleja en los índices de Transparencia Internacional y otras organizaciones que miden la corrupción, pero sí ocupa un espectro significativo de la agenda informativa sobre este tema, que tiene origen en el cubrimiento de ruedas de prensa y publicación de boletines. Mientras que la investigación originada en agenda propia es escasa.

La representación de la corrupción como una ilegalidad puede entenderse como una forma de "blanquear" el problema, en términos de color. La corrupción negra, que entiende el fenómeno como actos de corrupción a gran escala -que involucran a altos funcionarios públicos- corresponde a los resultados de Transparencia Internacional cuando califica a Colombia como un país "muy corrupto". Esto también indica que los medios consultados prefieren publicar información donde los hechos de corrupción tengan un mayor interés colectivo. El mensaje recurrente de algunas fuentes, al indicarle a la ciudadanía que "estamos luchando contra la corrupción" o "estamos tomando medidas", se complementa con una identificación de la corrupción como práctica ilegal: en la medida en que un juez no determine que efectivamente hubo una ilegalidad, no podría entonces afirmarse 
que hubo corrupción en virtud de la presunción de inocencia. Esta representación, que deja por fuera la posibilidad de que la corrupción sea un fenómeno más amplio y complejo que el mero ámbito penal -porque involucra conductas antiéticas o irregulares que no necesariamente están tipificadas- tiene como consecuencia que el relato se centre en seguir procesos judiciales y en incluir declaraciones relacionadas con dichos procesos, o con la ausencia de los mismos.

El sistema mediático, en su papel de intermediario ante la opinión pública, contribuye a configurar las maneras en las que la sociedad percibe el fenómeno de la corrupción y también puede influir en el diseño de las políticas públicas que se adoptan desde el sistema político para prevenir, controlar o sancionar este fenómeno. En ese orden de ideas, la conclusión de este estudio sobre la tendencia de los medios a hablar de hechos de corrupción distantes en el tiempo y en la geografía -mientras que los hechos de corrupción locales o inmediatos tienen menor registro- resulta relevante: este hecho, sumado a las declaraciones permanentes de funcionarios que advierten en los medios sobre los avances en la lucha contra la corrupción, puede moldear la percepción que la opinión pública construye sobre este tema y llevarla a pensar que la corrupción es un fenómeno que ha disminuido o en el que hay avances, aunque no sea cierto.

La selección de fuentes y la agenda obligada que imponen las entidades públicas también puede llevar a construir una percepción sobre la corrupción como un fenómeno que involucra principalmente a entidades y funcionarios públicos. Este estudio no busca caracterizar la corrupción, identificar sus causas o analizar la manera en la que los ciudadanos perciben el fenómeno, pero desde la forma en que los medios abordan los asuntos relacionados con la corrupción, se evidencia que hay un énfasis en la corrupción política y que la investigación, registro o mención de corrupción en el ámbito privado es apenas marginal.

De igual manera, se evidenció que los medios de comunicación reproducen el fenómeno de la corrupción desde sus diferentes formas de manifestación, puesto que los actos de corrupción son variados y pueden incluir prácticas como el pago de dinero extra a un funcionario del estado para acelerar un trámite o como influenciar la aprobación de leyes que beneficien a un grupo específico de individuos.

Por último, llama la atención que, aunque la observación se centró en medios con soporte digital, el uso de recursos digitales e interactividad es aún bastante escaso. El concepto de Castells sobre comunicación digital, como un entorno que conecta interactivamente a receptores y emisores, no se alcanza a percibir claramente en los medios observados: en la mayoría de los casos, el entorno web funciona como un archivo de textos con algún complemento gráfico estático (es significativamente más frecuente el uso de fotos que de audios, videos o elementos interactivos como hipervínculos) y no se aprovecha como un espacio de interrelación con las audiencias. Sobre este tema, valdría la pena en el futuro profundizar la investigación con entrevistas semiestructuradas, realizadas en las salas de redacción de los medios digitales locales, con el fin de comprender por qué el aprovechamiento de las herramientas digitales es aún tan incipiente.

\section{Referencias bibliográficas}

Álvarez, E. (1999). El rol de los medios de comunicación en la lucha contra la corrupción. Una perspectiva desde la sociedad civil. Instituto Interamericano de Derechos Humanos, 1(1), 219-239. Recuperado de http://www. corteidh.or.cr/tablas/al2038.pdf

Ángel, A. y Bates, B. (2014). Terministic Screens of Corruption: A Cluster Analysis of Colombian Radio Conversations. Ohio University, 10(1), 1-18.

Ángel, A. y Fuentes, A. (2015). Percepciones sobre la corrupción de habitantes de Manizales y Pereira. Papel Político, 20(1), 127-146. http://dx.doi.org/10.11144/Javeriana

Bourdieu, P. (1991). El sentido práctico. Madrid, España: Taurus. 
Tratamiento informativo de la corrupción en los medios digitales de Manizales, Colombia

Bourdieu, P. (1995). Respuestas por una antropología reflexiva. Ciudad de México, México: Grijalbo.

Bourdieu, P. (1997). Capital cultural, escuela y espacio social. Madrid, España: Siglo XXI editores.

Brei, Z. (1996). Corrupção: dificuldades para definição e para um consenso. Revista de Administração Pública, $30(1), 64-77$.

Brito, R. (2016). Corrupción: 21 puntos para el análisis reflexivo en el mundo actual. El cotidiano, 198(1), $39-42$.

Bryant, J. y Zillmann, D. (1996). Los efectos de los medios de comunicación. Barcelona, España: Editorial Paidós.

Canavilhas, J. (2007). Web journalism: from the inverted pyramid to the tumbled pyramid. Covilhā, Portugal: Biblioteca On-line de ciencias da comunicaçao. Recuperado de http://www.bocc.ubi.pt/pag/canavilhas-joaoinverted-pyramid.pdf

Caracol Radio. (2018, 21 de febrero). Ordenan investigar a Hernán Penagos y suspenden directivo del Sena Caldas. Recuperado de http://caracol.com.co/emisora/2018/02/22/manizales/1519257997_279073.html

Caracol Radio. (2018, 8 de mayo). Órganos de control le 'ponen el ojo' a 11 posibles hechos de corrupción. Recuperado de http://caracol.com.co/emisora/2018/05/09/manizales/1525819815_480256.html

Castells, M. (2006). La sociedad red. Madrid, España: Alianza Editorial.

Castillo, A. (2011). Relaciones públicas, Teoría e historia. Madrid, España: Editorial UOC.

Chibnall, S. y Saunders, P. (1977). Worlds apart: Notes on the social reality of corruption. The British Journal of Sociology, 28(2), 138-154. http://doi.org/10.2307/590207

Codina, L., Pedraza, R., Díaz, J., Rodríguez, R., Pérez, M. y Cavaller, V. (2014). Sistema Articulado de Análisis de Cibermedios (SAAC): Una propuesta sobre el qué y el cómo para estudiar medios de comunicación digitales. Revista académica sobre documentación digital y comunicación interactiva, 12(1), 1-15. http://doi. org/10.2436/20.8050.01.13

El Espectador. (2018, 4 de julio). Encuesta Gallup Poll de junio: mejora el estado de ánimo de los colombianos. Recuperado de https:/www.elespectador.com/noticias/politica/ encuesta-gallup-poll-de-junio-mejora-el-estado-de-animo-de-los-colombianos-articulo-798247

El Tiempo. (2018, 5 de abril). Corrupción le ha costado al país el 4 por ciento del PIB: Procurador. Recuperado de http://www.eltiempo.com/justicia/investigacion/corrupcion-le-ha-costado-al-pais-el-4-por-ciento-del-pibprocurador-201534

Fernández, J. (2012). Capital simbólico, dominación y legitimidad. Las raíces weberianas de la sociología de Pierre Bourdieu. Universidad Complutense de Madrid, 98(1), 33-60. http://dx.doi.org/10.5565/rev/papers/ v98n1.342

FLIP -Fundación para la libertad de prensa-. (2018). Prensa acorralada y juego de violentos y poderosos. Informe sobre el estado de la libertad de prensa en Colombia 2018. Recuperado de https://www.flip.org.co/micrositios/ informe-2018/descargas/informe-anual-2018.pdf

Franco, J. (2016). Medios de comunicación tradicionales en el nuevo entorno digital. León, España: Universidad de León.

Gaibar, L. (2015). Periodismo de investigación política en nuevos medios. Miguel Hernández Communication Journal, 5(1), 91-128. http://dx.doi.org/10.21134/mhcj.voi6.114

García, E. (2018). Perfil de la audiencia de cibermedios: Representación discursiva y praxis del receptor 2.0. Palabra Clave, 21(1), 111-133. http://doi.org/10.5294/pacla.2018.21.1.6 
Glaser, B. y Strauss, A. (1967). The Discovery of Grounded Theory: Strategies for Qualitative Research. New York/ Chicago, US: Aldine Publishing Company.

González, X. (2007). El poder simbólico de los medios de comunicación. Dikaiosyne, 19(1), 29-38.

Hoffman, D. y Novak, T. (1996). Marketing in Hypermedia Computer-Mediated Environments: Conceptual Foundations. Journal of Marketing, 60(3), 50-68. http://doi.org/10.2307/1251841

Jensen, J. (1998). Interactivity: Tracking a New Concept in Media and Communication Studies. Nordic Information Centre for Media Communication Research, 19(1), 185-204.

La Patria. (2017, 2 de mayo). Caldas tiene riesgo medio de corrupción. Recuperado de http://www.lapatria.com/ caldas/caldas-tiene-riesgo-medio-de-corrupcion-362906

Lozano, J. (1997). Teoría e investigación de la comunicación de masas. Ciudad de México, México: Alambra Mexicana.

Martínez, F. (2016). Los medios de comunicación y la lucha contra la corrupción. RVAP, 104(2), $163-198$.

Masip, P., Díaz-noci, J., Domingo, D., Micó-Sanz, J. y Salaverría, R. (2010). Investigación internacional sobre ciberperiodismo. Hipertexto, interactividad, multimedia y convergencia. El profesional de la información, 19(6), 568-576. https://doi.org/10.3145/epi.2010.nov.02

Meyer, J. (2009). Establecimiento de agendas en medios de comunicación. Revista Latina de Comunicación Social, 12(64), 15-28. http://doi.org/10.4185/RLCS-64-2009-801-15-28

Montiel, M. (2000). Los cibermedios como nuevas estructuras de comunicación social. Opción, 16(33), 34-48.

Pareja, V. (2003). Guía de Internet para periodistas. Madrid, España: CINDOC.

Paz, A., Romero, S., Díaz, B., Rojas, L. y Vargas, M. (2009). Tratamiento informativo de los principios básicos organizacionales de Venezuela realizado por los canales de televisión públicos y privados. Revista Científica Ciencias Sociales y Humanas, 5(78), 1-14.

Perez, T. y Da Silva, G. (2015). Corrupción en la función pública: un estudio sobre correlaciones entre corrupción, calidad de la democracia, gobernanza, desigualdad de renta y desempleo en el mundo (2008-2012). Revista Colombiana de Ciencias Sociales, 6(1), 15-33. https://doi.org/10.21501/22161201.1340

Ramos, C. (1995). Los medios de comunicación, agentes constructores de lo real. Comunicar, 9(5), 108-112.

Rivas, M. (1999). Géneros periodísticos en las agencias de prensa. Estudios sobre el mensaje periodístico, 2(5), 159-167.

Ruiz, A. y Albertini, E. (2008). Fuentes periodísticas: concepto, clasificación y modos de uso. Revista de Comunicación y Cultura, 60(2), 14-25. Recuperado de http://hdl.handle.net/10915/36422

Salaverría, R. (2017). Tipología de los cibermedios periodísticos: bases teóricas para su clasificación. Revista Mediterránea de Comunicación, 8(1), 19-32. https://doi.org/10.14198/MEDCOM2017.8.1.2

Solimano, A., Tanzi, V. y Del Solar, F. (2008). Las termitas del Estado: ensayos sobre corrupción, transparencia y desarrollo. Santiago, Chile: Fondo de Cultura Económica.

Tirado, N. (2016). Corrupción y fuentes informativas en medios tradicionales y nativos Digitales. Miguel Hernández Communication Journal, 83(11), 257-285. http://dx.doi.org/10.21134/mhcj.voi7.117

Transparencia Internacional. (2018). Índice de percepción de la corrupción, resultados 2017. Recuperado de https://www.transparency.org/news/pressrelease/el_indice_de_percepcion_de_la_corrupcion_2017_ muestra_una_fuerte_presencia 
Túñez, M. y Martínez, M. (2014). Análisis del impacto de la función, las actitudes y las condiciones laborales del periodista en la producción de noticias: hacia un periodismo de empresa. Zer, 19(36), 37-54.

Unesco -Organización de las Naciones Unidas para la Educación, la Ciencia y la Cultura-. (2016). Los medios de comunicación. Recuperado de http://www.unesco.org/new/es/education/themes/ leading-the-international-agenda/education-for-sustainable-development/partners/media/

Vargas, J. (2009). The multiple faces of corruption: Typology, forms and levels. Contemporary Legal \& Economic, 15(3), 269-290. http://dx.doi.org/10.2139/ssrn.1413976

White, R. (2013). What Counts as Corruption? Social Research: An International Quarterly, 80(4), 1033-1056. 